\title{
Enzymatic modifications of exopolysaccharides enhance bacterial persistence
}

\author{
Gregory B. Whitfield ${ }^{1,2+}$, Lindsey S. Marmont ${ }^{1,2+}$ and P. Lynne Howell ${ }^{1,2 *}$ \\ ${ }^{1}$ Program in Molecular Structure and Function, Research Institute, The Hospital for Sick Children, Toronto, ON, Canada, \\ ${ }^{2}$ Department of Biochemistry, Faculty of Medicine, University of Toronto, Toronto, ON, Canada
}

\section{OPEN ACCESS}

Edited by:

Jochen Schmid,

Technische Universität München,

Germany

Reviewed by:

Wensheng Lan,

Shenzhen Entry-Exit Inspection and Quarantine Bureau, China

Hans-Curt Flemming,

University of Duisburg-Essen,

Germany

*Correspondence:

P. Lynne Howell,

Program in Molecular Structure and Function, Research Institute,

The Hospital for Sick Children,

686 Bay Street, Toronto,

ON M5G OA4, Canada

howell@sickkids.ca

${ }^{\dagger}$ These authors have contributed equally to this work.

Specialty section

This article was submitted to Microbiotechnology, Ecotoxicology and Bioremediation,

a section of the journal

Frontiers in Microbiology

Received: 11 March 2015 Accepted: 29 April 2015 Published: 15 May 2015

Citation:

Whitfield GB, Marmont LS and Howell PL (2015) Enzymatic modifications of exopolysaccharides enhance bacterial persistence.

Front. Microbiol. 6:471. doi: 10.3389/fmicb.2015.00471
Biofilms are surface-attached communities of bacterial cells embedded in a selfproduced matrix that are found ubiquitously in nature. The biofilm matrix is composed of various extracellular polymeric substances, which confer advantages to the encapsulated bacteria by protecting them from eradication. The matrix composition varies between species and is dependent on the environmental niche that the bacteria inhabit. Exopolysaccharides (EPS) play a variety of important roles in biofilm formation in numerous bacterial species. The ability of bacteria to thrive in a broad range of environmental settings is reflected in part by the structural diversity of the EPS produced both within individual bacterial strains as well as by different species. This variability is achieved through polymerization of distinct sugar moieties into homo- or hetero-polymers, as well as post-polymerization modification of the polysaccharide. Specific enzymes that are unique to the production of each polymer can transfer or remove non-carbohydrate moieties, or in other cases, epimerize the sugar units. These modifications alter the physicochemical properties of the polymer, which in turn can affect bacterial pathogenicity, virulence, and environmental adaptability. Herein, we review the diversity of modifications that the EPS alginate, the Pel polysaccharide, Vibrio polysaccharide, cepacian, glycosaminoglycans, and poly- $\mathrm{N}$-acetyl-glucosamine undergo during biosynthesis. These are EPS produced by human pathogenic bacteria for which studies have begun to unravel the effect modifications have on their physicochemical and biological properties. The biological advantages these polymer modifications confer to the bacteria that produce them will be discussed. The expanding list of identified modifications will allow future efforts to focus on linking these modifications to specific biosynthetic genes and biofilm phenotypes.

Keywords: Biofilm, exopolysaccharide, PNAG, PIA, alginate, PEL, VPS, cepacian

Abbreviations: Bcc, Burkholderia cepacia complex; CF, cystic fibrosis; CPS, capsular polysaccharide; EPS, exopolysaccharide; G-blocks, guluronate blocks; GAGs, glycosaminoglycans; GBS, Group B Streptococcus; GlcA, glucuronic acid; GulA, guluronate; GulNAcA, N-acetyl guluronate; HS, heparan sulfate; IdoA, iduronic acid; LPS, lipopolysaccharide; M-blocks, mannuronate blocks; ManA, mannuronate; MBOAT, membrane-bound O-acetyltransferase; MG-blocks, mixed mannuronate and guluronate blocks; PEL, pel polysaccharide; PIA, polysaccharide intercellular adhesin; PNAG, poly- $N$ acetylglucosamine; polyM, polymannuronate; ROS, reactive oxygen species; VPS, Vibrio polysaccharide. 


\section{Introduction}

Bacteria faced with fluctuating or stressful environmental conditions can undergo a number of physiological changes. One common tactic that bacteria use to adapt to their surroundings is to grow as a multicellular community or biofilm. Biofilm formation begins with attachment of the bacteria to a surface or, in the case of some infectious biofilms, embedding of the bacteria in host-derived tissue or mucous. This is followed by bacterial aggregation, colony development, and the secretion of self-produced polymeric substances, which form a matrix that encapsulates and protects the bacteria (Ohman, 1986; Allesen-Holm et al., 2006). This matrix is composed of nucleic acids, proteins, lipids, and extracellular polysaccharides (EPS; Flemming and Wingender, 2010), with the types and ratio of each component varying between bacterial species and environmental conditions. Once the biofilm has matured into a robust structure it becomes exceedingly difficult to eradicate, and is typically capable of enduring mechanical, biological, and chemical means of elimination. Bacteria form biofilms in nearly all environments studied to date (Bjarnsholt et al., 2013b), and are implicated in the contamination of surfaces as diverse as the International Space Station (Kim et al., 2013), ship hulls (Schultz et al., 2011), and oil storage and transfer infrastructure (Lenhart et al., 2014). Biofilms are also of major concern in medical settings, where they are responsible for the chronic infection of burn wounds, eye and skin lacerations, and pneumonia in CF patients (Lyczak et al., 2000). The contamination of medical devices such as catheters, prosthetic joints, and ventilators (Veerachamy et al., 2014) has also been well documented. In these environments EPS often contribute to the formation, growth, and preservation of biofilm architecture and also serve to protect the bacteria against antibiotics, desiccation, and the host's immune defenses.

Biosynthesis of EPS begins in the cytoplasm with the generation of activated precursor sugars. These precursors are often taken from common cellular sugar pools and are modified for specific use in EPS biosynthesis pathways, prior to polymerization (Figure 1). In Gram-negative bacteria, the polymer is transported across the inner membrane to the periplasm during synthesis; whereas in Gram-positive bacteria the polymer is transported directly to the extracellular space. Modifications to the polymer can occur in the cytoplasm (Atkin et al., 2014) or the periplasm (Colvin et al., 2013; Baker et al., 2014; Little et al., 2014b; Wolfram et al., 2014) prior to export across the outer membrane, and in the extracellular space in both Gram-positive and Gram-negative bacteria (Rozeboom et al., 2008; Little et al., 2014a).

The chemical structure of EPS from different bacterial species, or even within the same organism, can vary greatly. Bacterial EPS are usually composed of hexose sugars, but pentose sugars

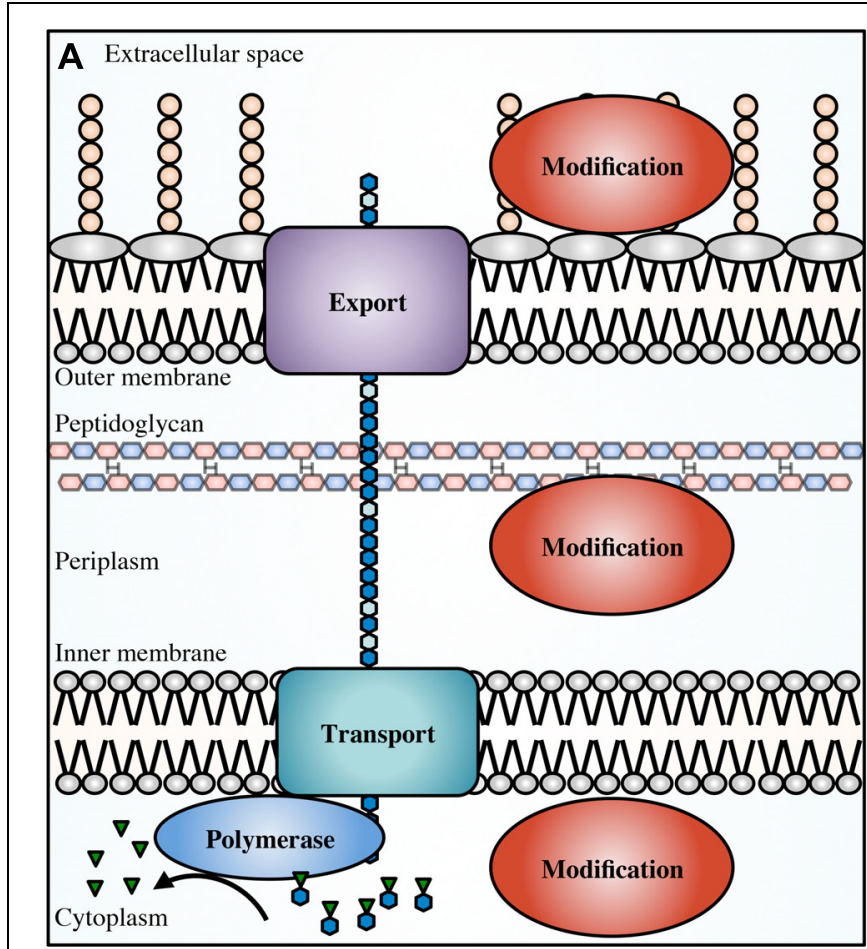

FIGURE 1 | Generalized EPS biosynthetic platforms. Not to scale. In Gram-negative bacteria (A) modifications to the polymer can occur in the cytoplasm, periplasm and in the extracellular space. In Gram-positive bacteria (B) modifications can occur in the cytoplasm and extracellular space. Polymer biosynthetic systems are represented here as follows: activated sugars (blue hexagons with green inverted triangles) are assembled by a polymerase (blue),

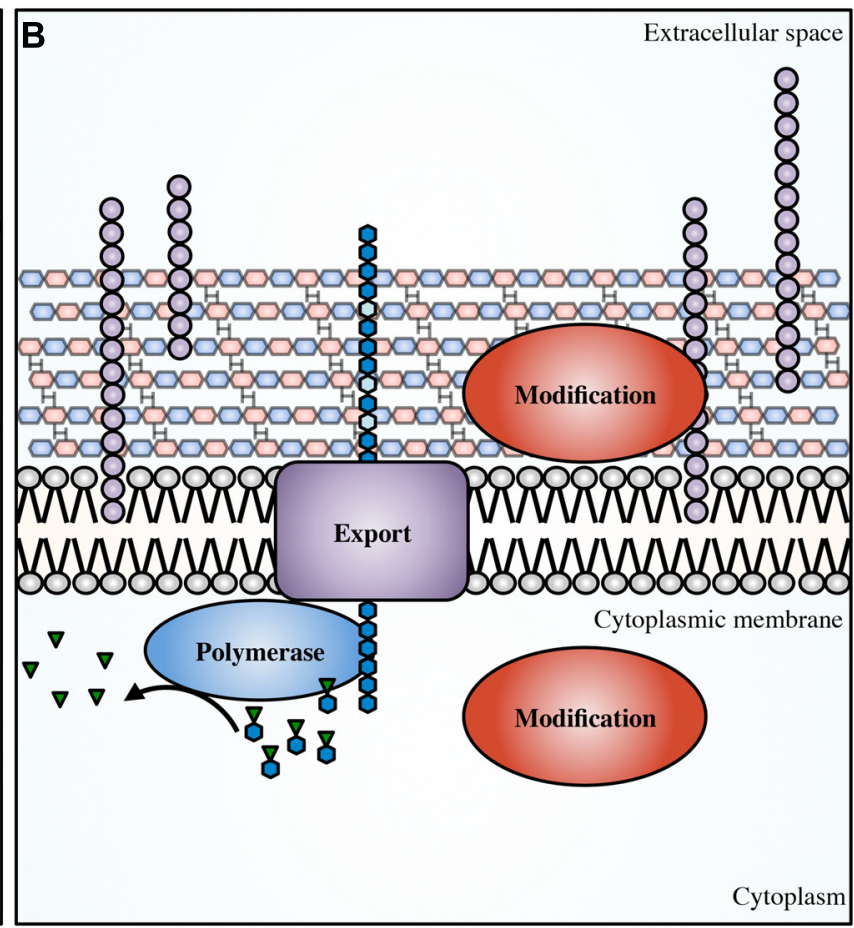

transported across the inner membrane (teal; polymerization and transport may be coupled and performed by a single protein), and exported (purple) across the outer membrane in Gram-negative bacteria, or exported across the cytoplasmic membrane in Gram-positive bacteria. Modifications can be performed in any of these cellular compartments (red). Also shown, LPS (tan circles), teichoic acids (light purple circles), and EPS (blue hexagons). 
have also been identified. Rhizobium huakuii EPS contains ribose (Hisamatsu et al., 1997), while some marine bacteria produce EPS with xylose and ribose moieties (Kwon et al., 2002). EPS can be homo- or hetero-polymers, and have branching side chains (Byrd et al., 2009; Cescutti et al., 2010) or be simple linear sugar polymers (Linker and Jones, 1966; Maira-Litràn et al., 2002). They can be as short as dimers and trimers, or thousands of saccharide repeat units long (González et al., 1998), depending on the mechanisms of chain length regulation, and can even be woven together to form fibers (Benziman et al., 1980).

Exopolysaccharides can be modified by the action of transferases and hydrolases which add or remove functional groups such as acetyls, pyruvyls (Marzocca et al., 1991), glyceryls (Kuo et al., 1986), succinyls (Reuber and Walker, 1993), lactyls (Maalej et al., 2014), or a combination of these, leading to variations in polymer surface electrostatics and solubility. Additionally, epimerization can drastically alter the structural conformation of polysaccharides, affecting polymer interactions within the biofilm (Steigedal et al., 2008). Some of these modifications have been studied with respect to their importance in bacterial virulence, pathogenesis, biofilm formation, or symbiosis (Figure 2; Ridout et al., 1997), as well as their commercial utility in the food and cosmetic industries.

Despite this wealth of knowledge, there remain a number of unresolved questions regarding the biological implications of EPS modifications. In this review, we explore the modifications that biofilm-forming EPS produced by human pathogenic bacteria undergo and discuss the proteins involved in modification, as well as the role modifications play in bacterial persistence in the environment and host.

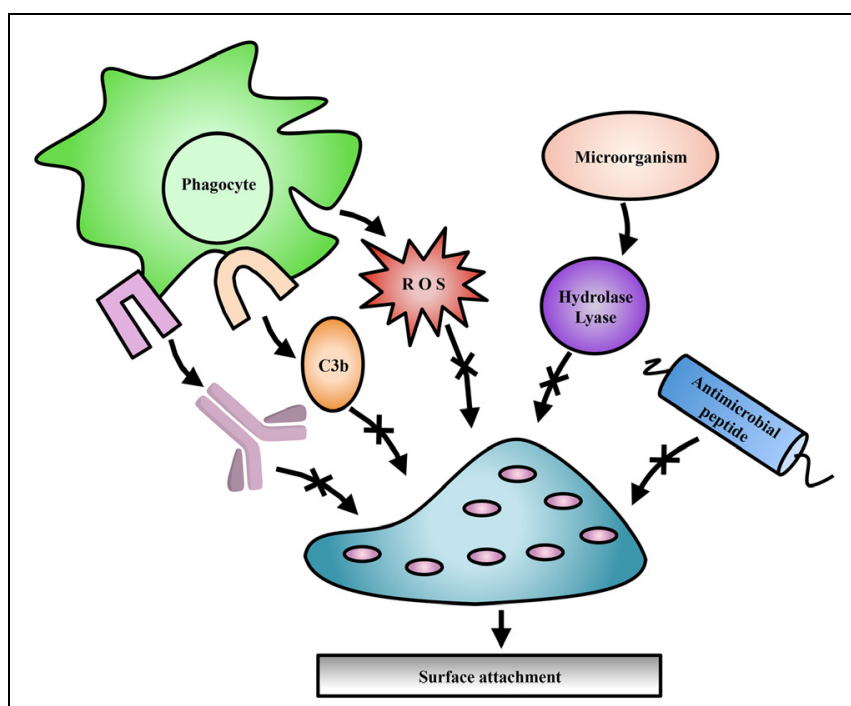

FIGURE 2 | Exopolysaccharide modifications offer protection to bacteria. Modifications to EPS contribute to evasion of host immune mechanisms such as complement deposition (C3b), and specific antibody production (lavender). Modifications have also been shown to protect against ROS produced by immune cells, antimicrobial peptides, and EPS degradation enzymes produced by competing microorganisms.

\section{Alginate}

Alginate synthesis has been characterized in several species of brown algae, as well as in the genera Azotobacter and Pseudomonas (Gorin and Spencer, 1966; Evans and Linker, 1973; Govan et al., 1981; Gacesa, 1988). Bacterial alginate is a high molecular weight, linear polysaccharide composed of $\beta$-1,4-linked D-ManA and variable amounts of its C5 epimer LGulA (Smidsrød and Draget, 1996). In Pseudomonas aeruginosa and Azotobacter vinelandii, alginate is initially synthesized as polyM in the cytoplasm and is shuttled across the inner membrane to the periplasm, where it is randomly acetylated at the $\mathrm{O} 2$ and/or $\mathrm{O} 3$ hydroxyl positions (Table 1; Figure 3; Franklin and Ohman, 1993, 1996, 2002). ManA residues that are not acetylated serve as substrates for epimerization at the C5 position by the enzyme AlgG in the periplasm, leading to the formation of mixed ManA and GulA segments (MG-blocks) as well as non-epimerized sections (M-blocks; Gacesa, 1988; Jain et al., 2003).

Pseudomonas aeruginosa chronic lung infections in CF patients are the leading cause of morbidity and mortality. In these infections the production of alginate is often linked to poorer patient prognosis (Lyczak et al., 2000). In the lung, the clinical isolate $P$. aeruginosa FRD1 displays an alginate-overproducing, or mucoid phenotype due to mutations in negative regulatory elements, providing P. aeruginosa with the capability of adhering to respiratory tract epithelial cells and mucin (Marcus and Baker, 1985; Doig et al., 1987; Ramphal et al., 1987). In addition, alginate production has been linked to the hindrance of host cellmediated phagocytosis and neutralization of ROS (Learn et al., 1987; Mai et al., 1993; Pier et al., 2001). Mucoid conversion is still not well understood, but in vitro experimentation has shown that nutrient and aeration levels (Buckmire, 1984; Krieg et al., 1986; Speert et al., 1990) and external stressors (Terry et al., 1991; Damron et al., 2011; Limoli et al., 2014) can induce mucoidy.

Azotobacter vinelandii is a soil-borne bacterium that is often used as a model organism for nitrogen fixation studies (Bulen et al., 1964). Although A. vinelandii is not a human pathogen, understanding the process of alginate biosynthesis in this organism has provided valuable insight into the biological significance of alginate production by $P$. aeruginosa. In $A$. vinelandii, alginate plays a unique and essential role where, under conditions of nutrient and environmental stress such as nitrogen starvation, $A$. vinelandii converts from a vegetative cell to a dormant cyst (Socolofsky and Wyss, 1961). Cyst development proceeds through deposition of a protective extracellular material composed primarily of alginate. The cyst layers are rich in proteins, lipids and carbohydrates, with the exine (outer layer) and intine (inner layer) containing carbohydrate material consisting of approximately 40 and $72 \%$ polyuronic acids, respectively (Lin and Sadoff, 1969). Cyst formation, much like the biofilm matrix, protects A. vinelandii from desiccation, and only when environmental conditions become more favorable will A. vinelandii convert back to the vegetative state by degrading the alginate barrier. In contrast to $P$. aeruginosa, $A$. vinelandii contains seven additional extracellular epimerases (AlgE1-7), 


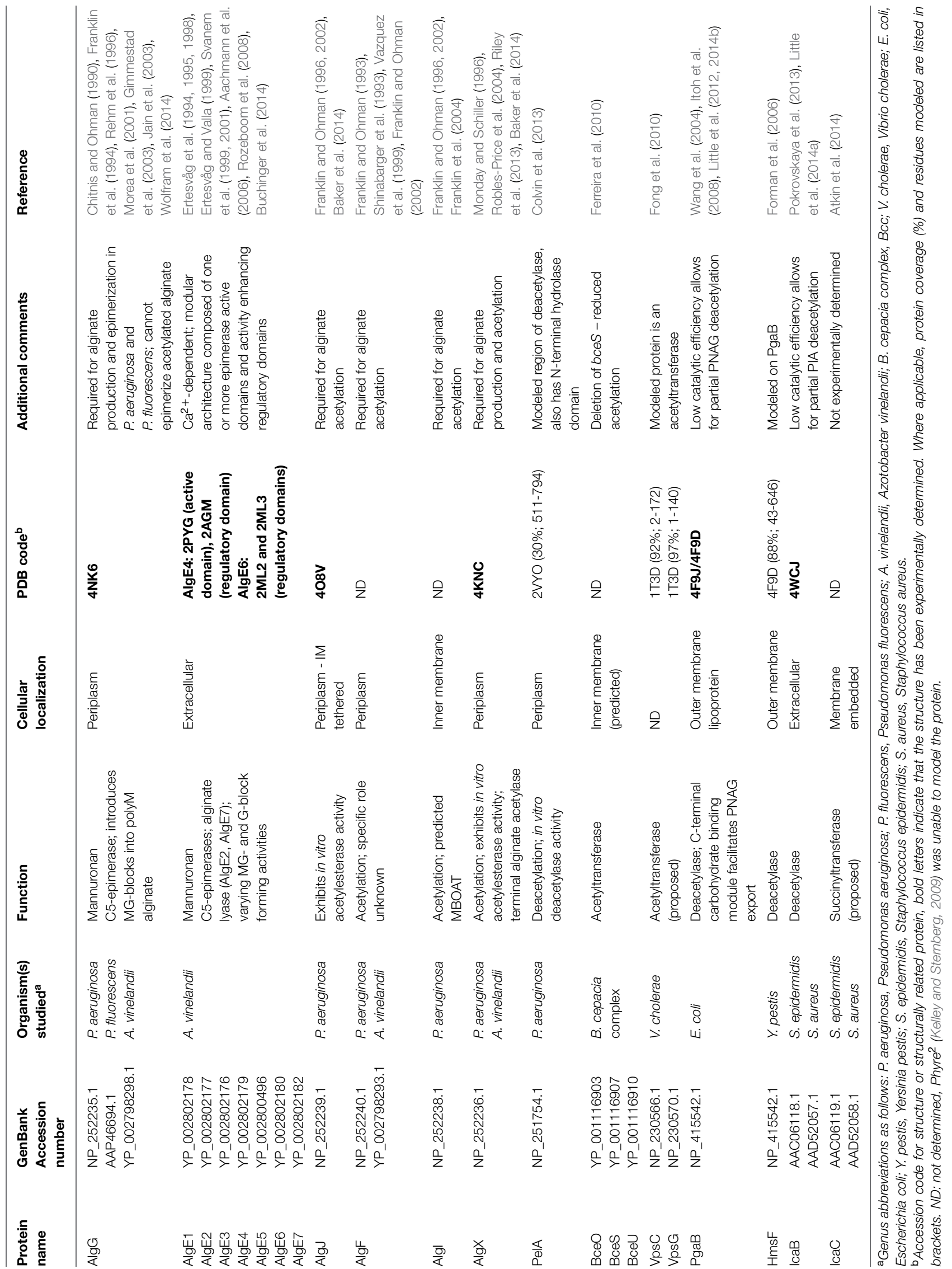




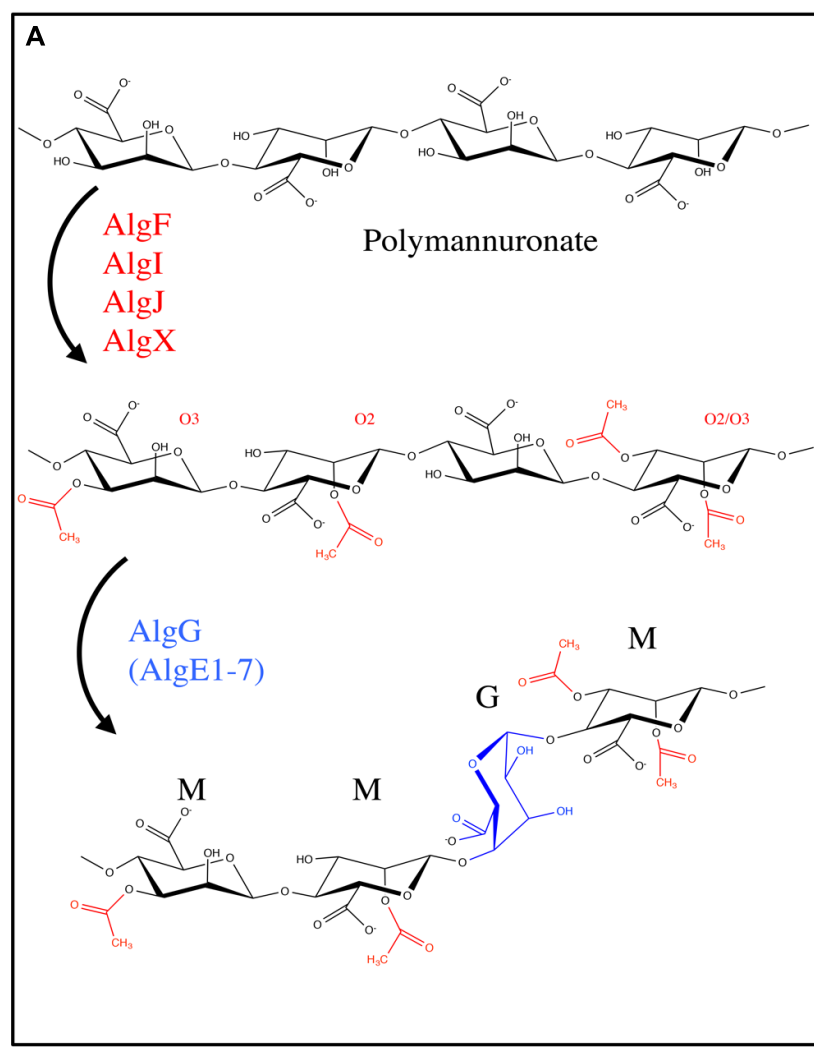

FIGURE 3 | Pseudomonal alginate modifications and biosynthetic apparatus. Not to scale. (A) Alginate is first polymerized as $\beta$-sCD- $(1 \rightarrow 4)$-polyM (top) before being acetylated at the $\mathrm{O} 2$ and/or $\mathrm{O} 3$ positions by the concerted actions of AlglJFX. Acetylated ManA residues (middle) cannot be epimerized to L-GulA by AlgG (bottom). (B) The proteins involved in alginate biosynthesis in Pseudomonas aeruginosa. PolyM (green hexagon chain) is synthesized in the

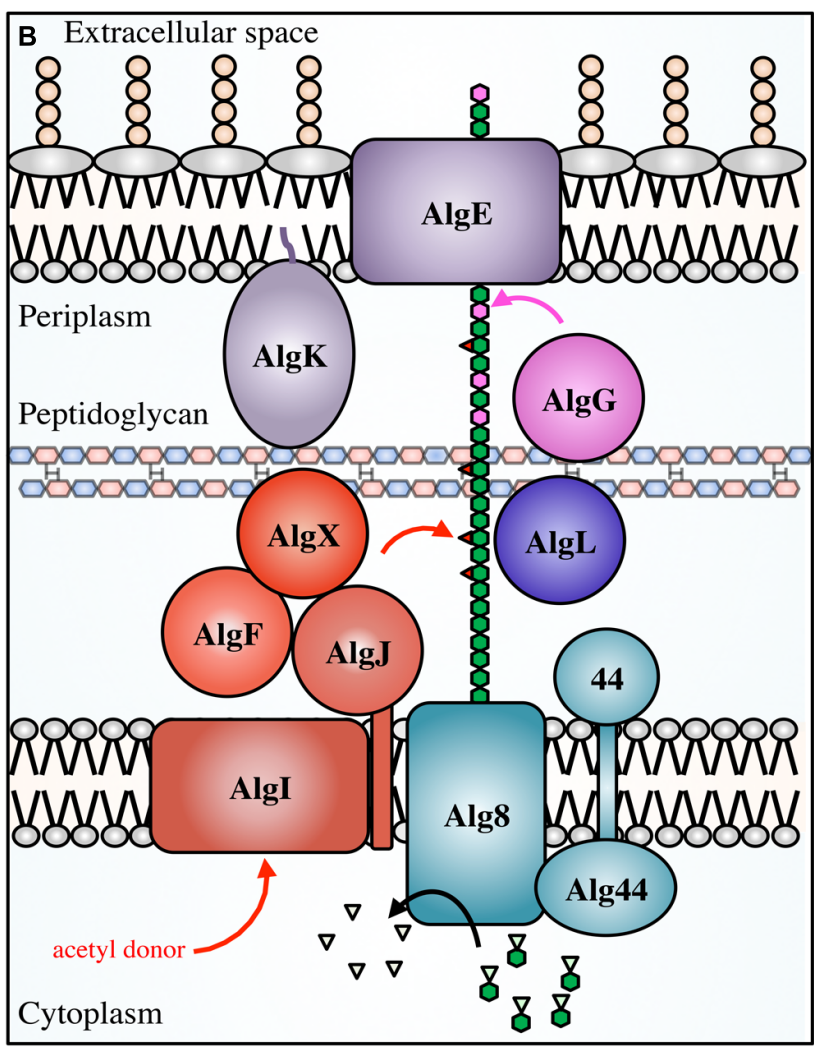

cytoplasm from the nucleotide-sugar precursor GDP-ManA (green hexagons with inverted triangles). It is polymerized, and transported across the inner membrane via Alg8/44, acetylated (red triangles) by the concerted action of AlgFIJX, and epimerized to GulA (magenta) by AlgG. AlgL possesses lyase activity; AlgK is a lipoprotein required for efficient localization of AlgE, the porin required for alginate export. capable of generating polyguluronate segments (G-blocks) in addition to MG-blocks (Table 1; Fischer and Dorfel, 1955; Haug et al., 1966, 1967). Despite the importance of alginate in cyst formation (Campos et al., 1996), alginate production by A. vinelandii has been studied primarily for its potential use as an alternative source of commercial alginate in place of traditional seaweed harvesting approaches.

Given the importance of alginate for the virulence of $P$. aeruginosa in the $\mathrm{CF}$ lung, the protective characteristics of $A$. vinelandii cysts, and the use of bacterial alginate as a convenient substitute for commercial eukaryotic alginate sources, there has been a drive to understand the consequences of alginate acetylation and epimerization on these processes.

\section{Alginate Acetylation}

Alginate acetylation in $P$. aeruginosa requires the collective actions of the proteins AlgF, AlgI, AlgJ, and AlgX for the addition of acetyl groups to the $\mathrm{O} 2$ and/or $\mathrm{O} 3$ hydroxyl positions of polyM in the periplasm prior to epimerization and export (Table 1; Figure 3). Specifically, it is thought that AlgI transfers an acetyl group from an as yet unidentified cytoplasmic donor to AlgJ or AlgX, where it may be passed between them before transfer to the polymer by AlgX (Riley et al., 2013; Baker et al., 2014). AlgF is an important part of the acetylation process but has not yet been assigned a role. Based on the peptidoglycan $O$-acetylation machinery (Moynihan and Clarke, 2011), it seems that the presence of a MBOAT for acetyl-donor transport $(\mathrm{Alg} \mathrm{I})$, and an acetyltransferase $(\mathrm{AlgX})$ should be sufficient for polysaccharide $\mathrm{O}$-acetylation. As acetylation occurs at both the $\mathrm{O} 2$ and $\mathrm{O} 3$ positions, one hypothesis is that the proteins AlgJ and AlgF govern specificity. Although they have not yet been shown to directly bind alginate, they may still be able to regulate the position and frequency of acetyl addition under different environmental conditions. Genetic and biochemical experiments targeting the degree of alginate acetylation in combination with structural data may provide insight into these questions.

One of the purposes of EPS production is to serve as a structural component of the biofilm matrix. Alginate lacking $O$-acetyl groups has been analyzed for its ability to form structured biofilms using an acetylation defective $P$. aeruginosa FRD1 mutant. These studies revealed that the mutant was only 
TABLE 2 | Biological implications of EPS modifications.

\begin{tabular}{|c|c|c|c|c|}
\hline Modification & Proteins involved & Organism studied & Implication of modification & Reference \\
\hline \multicolumn{5}{|l|}{ Alginate } \\
\hline \multirow[t]{7}{*}{ Acetylation } & AlgF, Algl, AlgJ, AlgX & $\begin{array}{l}\text { Pseudomonas } \\
\text { aeruginosa }\end{array}$ & $\begin{array}{l}\text { Required for surface attachment and formation of } \\
\text { structured microcolonies }\end{array}$ & $\begin{array}{l}\text { Nivens et al. (2001), Tielen } \\
\text { et al. (2005) }\end{array}$ \\
\hline & & & Increased polymer viscosity & Tielen et al. (2005) \\
\hline & & & $\begin{array}{l}\text { Decreased neutrophil locomotion and lymphocyte } \\
\text { transformation }\end{array}$ & Mai et al. (1993) \\
\hline & & & $\begin{array}{l}\text { Reduced activation of complement and opsonic killing } \\
\text { by phagocytes }\end{array}$ & Pier et al. (2001) \\
\hline & & & Scavenging of ROS & Learn et al. (1987) \\
\hline & & & Reduced susceptibility to enzymatic degradation & Farrell and Tipton (2012) \\
\hline & & & Increased gel thickness & Skjåk-Braek et al. (1989) \\
\hline \multirow[t]{5}{*}{ Epimerization } & $\begin{array}{l}\text { AlgG, AlgE1-7 (Azotobacter } \\
\text { vinelandii) }\end{array}$ & $P$. aeruginosa & Improved gel forming ability (cohesion) & $\begin{array}{l}\text { Grant et al. (1973), Donati } \\
\text { et al. (2005) }\end{array}$ \\
\hline & & & $\begin{array}{l}\text { Upregulation of virulence factors through } \mathrm{Ca}^{2+} \\
\text { sequestration }\end{array}$ & Horsman et al. (2012) \\
\hline & & A. vinelandii & $\begin{array}{l}\text { Maintain biofilm structure during changing } \\
\text { environmental conditions }\end{array}$ & Ertesvåg et al. (1998) \\
\hline & & & Preserve $\mathrm{N}_{2}$-fixing capability & Sabra et al. (2000) \\
\hline & & & Required for formation of functional cyst coat & Steigedal et al. (2008) \\
\hline \multicolumn{5}{|l|}{ PEL } \\
\hline Deacetylation & PelA & $P$. aeruginosa & Required for biofilm formation (in PSL deficient strains) & Colvin et al. (2013) \\
\hline \multicolumn{5}{|l|}{ Cepacian } \\
\hline \multirow[t]{2}{*}{ Acetylation } & BceOSU & $B c c$ & Reduced susceptibility to enzymatic degradation & Cescutti et al. (2006) \\
\hline & & & Scavenging of ROS & Cuzzi et al. (2012) \\
\hline \multicolumn{5}{|c|}{ Vibrio polysaccharide (VPS) } \\
\hline Acetylation & VpsG & Vibrio cholerae & $\begin{array}{l}\text { Required for robust biofilm formation and wild-type } \\
\text { phenotypes }\end{array}$ & Fong et al. (2010) \\
\hline \multicolumn{5}{|c|}{ Poly-N-acetyl-glucosamine (PNAG) } \\
\hline \multirow[t]{8}{*}{ Deacetylation } & $\begin{array}{l}\text { PgaB (Escherichia coli), } \\
\text { HmsF (Yersinia pestis) IcaB } \\
\text { (Staphylococcus epidermidis } \\
\text { and S. aureus) }\end{array}$ & S. epidermidis & Required for biofilm formation and surface attachment & Vuong et al. (2004a) \\
\hline & & & Resistance to human cationic antimicrobial peptides & \\
\hline & & & Resistance to neutrophil phagocytosis & \\
\hline & & & Persistence in mouse model of infection & \\
\hline & & S. aureus & $\begin{array}{l}\text { Required for biofilm formation and surface attachment } \\
\text { Resistance to phagocytosis }\end{array}$ & Cerca et al. (2007) \\
\hline & & & Persistence in mouse model of infection & \\
\hline & & E. coli & Required for export of polymer and biofilm formation & Itoh et al. (2008) \\
\hline & & Y. pestis & Required for biofilm formation & Forman et al. (2006) \\
\hline Succinylation & IcaC & S. aureus & Modulation improves in vitro fitness & Brooks and Jefferson (2014) \\
\hline
\end{tabular}

able to produce small, unstructured microcolonies that sparsely populated the examined surface, suggesting an attachment defect (Table 2; Nivens et al., 2001). In contrast, FRD1 formed extensive biofilm structures that exhibited significant structural heterogeneity. In a separate study, an aggregation defect was revealed when the capacity for an acetylation-deficient FRD1 mutant to adhere to a steel surface was tested (Tielen et al., 2005). Additionally, the viscosity of extracellular material from the acetylation-defective mutant was significantly reduced in comparison to FRD1, suggesting that the loss of $O$-acetyl groups led to weakening of inter- and intra-polymer interactions within the biofilm matrix. This is supported by rheological studies of FRD1 biofilms, which suggested that inter-chain alginate interactions occur primarily through physical entanglements
(Wloka et al., 2005). These entanglements supported an elastic biofilm architecture, which differed from $O$-acetylation-defective FRD1 mutants which produced weaker biofilms with reduced resistance to tensile forces. Based on these results, it was suggested that $O$-acetyl groups in alginate act as molecular hooks that improve the resistance of the entangled alginate structural network against applied forces (Wloka et al., 2005). While the importance of alginate acetyl groups for cell aggregation and microcolony formation in vitro is well established, the influence of $O$-acetyl groups on biofilm formation phenotypes in clinically relevant $P$. aeruginos $a$ infections or related in vivo model systems of infection remain uncharacterized.

P. aeruginosa biofilm formation in the CF lung has been shown to provide significant protection from a variety of host immune 
factors. For example, decreased locomotion of neutrophils, as well as reduced lymphocyte transformation, have been observed when these cell types are incubated with alginate (Simpson et al., 1988). However, chemical removal of acetyl groups from alginate led to a complete loss of these inhibitory effects on neutrophil and lymphocyte function, suggesting that alginate $O$-acetylation is essential for their suppression (Mai et al., 1993). The activation of complement is also affected by the presence of acetyl groups (Pier et al., 2001). This is not surprising given that interactions between alginate and the complement component C3b likely occurs through unsubstituted hydroxyl groups (Hostetter et al., 1982), suggesting that the addition of acetyl groups to alginate in $P$. aeruginosa may have evolved as a mechanism for complement evasion. Activation of the alternative pathway of complement can lead to phagocytic killing, which is also impaired by the presence of $O$-acetyl groups. Opsonic killing of the FRD1 $O$-acetylation deficient mutant by phagocytes was readily observed, while wild-type FRD1 was resistant to these attacks (Pier et al., 2001). Alginate is also known to scavenge ROS produced by phagocytic cells during infection. Hypochlorite is a common ROS produced by phagocytes, and the presence of alginate in mucoid $P$. aeruginosa provides a significant protective advantage against hypochlorite over non-mucoid cells in vitro (Learn et al., 1987). This protective effect was, in part, attributed to the $O$-acetyl groups, as chemically deacetylated alginate exhibited impaired hypochlorite scavenging. Furthermore, addition of hypochlorite to native alginate led to a decrease in viscosity, similar to that seen for the chemically deacetylated alginate, suggesting that hypochlorite may be specifically reacting with $\mathrm{O}$-acetyl groups from native alginate (Learn et al., 1987).

When bacteria are contending for control of the same environment, they can release extracellular enzymes to degrade critical structural components of cohabiting organisms to give them a competitive advantage (Korotkov et al., 2012). This is observed in the CF lung, where instances of multispecies biofilms are common (Elias and Banin, 2012). During colonization of the CF lung, alginate acetyl groups may serve as a protective mechanism to prevent unwanted degradation of alginate within the biofilm by bacteria that could secrete an AlgL-like lyase as an offensive tactic. The $P$. aeruginosa alginate lyase AlgL preferentially degrades deacetylated alginate or polyM over mature, acetylated alginate (Farrell and Tipton, 2012). Furthermore, $O$-acetyl groups prevent the epimerization of ManA to GulA by the epimerases AlgE1-7 in A. vinelandii, which may allow for control over the degree of epimerization and, in turn, regulation of the cyst coat composition.

Alginate acetylation content ranges from 4 to $57 \%$, depending on the percentage of ManA present (Skjåk-Braek et al., 1986). The degree of $\mathrm{O}$-acetylation is often observed to vary not only between different alginate-producing organisms, but also between different strains of the same organism and even within the same strain under differing growth conditions (Marty et al., 1992; Peña et al., 2006). For example, modulation of carbon source during growth for a single alginate-producing $P$. syringae strain led to significant differences in acetyl content, ranging from 9 to $34 \%$ of total uronic acids bearing an acetyl group (Day, 1988). In another study, the alginate produced by several different strains of $P$. aeruginosa grown on nutritionally distinct media was examined. This study revealed that between different strains $O$-acetyl content of alginate varied between 2 to $56 \%$ (Marty et al., 1992). Furthermore, in both studies alginate acetyl content changed over the course of a single growth experiment by as much as $40 \%$, possibly owing to the availability of acetyl-CoA, the proposed acetyl donor (Lee and Day, 1998). In addition to acetyl-CoA availability, differences in acetyl content could conceivably be a means to optimize attachment, nutrient uptake, or nutrient diffusion within the biofilm in the face of different media compositions and nutrient sources. This notion is supported by findings which suggest that alginate $O$-acetylation can enhance the swelling ability of calcium alginate gels (SkjåkBraek et al., 1989). Deacetylated alginate exhibited poor swelling ability in comparison to chemically acetylated variants, with increasing degrees of acetylation leading to greater swelling volume. Conversely, increased $O$-acetylation led to a decrease in the affinity of alginate gels for calcium ions (Skjåk-Braek et al., 1989). Thus, alginate acetyl content has specific consequences with respect to calcium ion binding and the thickness of alginate gels, which may influence nutrient diffusion in the biofilm. These findings could potentially be extrapolated to other components of the growth media, and suggests a mechanism by which alginate-producing bacteria could regulate the uptake of essential nutrients.

\section{Alginate Epimerization}

Pseudomonas aeruginosa has a single alginate C5-epimerase in the periplasm, AlgG. In A. vinelandii, there is an AlgG ortholog that performs the same function, and seven additional extracellular epimerases, AlgE1 through AlgE7 (Table 1). Alginate can form strong gels through interactions with GulA residues, mediated by $\mathrm{Ca}^{2+}$ ions. This feature was thought to be limited to alginates containing G-blocks, and would therefore exclude the MG-block alginates produced by P. aeruginosa (Grant et al., 1973). However, it is now thought that alginates containing exclusively MG-blocks can also form gels in the presence of $\mathrm{Ca}^{2+}$ (Donati et al., 2005), suggesting that epimerization by $\mathrm{AlgG}$ in $P$. aeruginosa may serve as a mechanism to improve the cohesion of alginate during biofilm formation. It was found that addition of $\mathrm{CaCl}_{2}$ to growth media led to the production of biofilms that were 10- to 20-fold thicker than that produced in the absence of $\mathrm{Ca}^{2+}$ (Sarkisova et al., 2005). $\mathrm{Ca}^{2+}$-alginate interactions also regulate virulence factor expression, as chelation of $\mathrm{Ca}^{2+}$ by alginate induces expression of the Type 3 secretion system (Horsman et al., 2012). Therefore, it appears that there are mechanisms in place in P. aeruginosa for virulence factors to be upregulated by the expression of another, thus allowing for concerted actions that improve fitness (Table 2). Despite advances in understanding the interplay between $\mathrm{Ca}^{2+}$ and alginate in P. aeruginosa, and the extensive studies performed on acetyl-deficient alginate, there are no reports on the effects of epimerization on biofilm formation, pathogenicity, or virulence.

In contrast, the role of epimerization in $A$. vinelandii cyst formation has been well characterized. One hypothesis regarding 
the ability of $A$. vinelandii to express multiple epimerases with unique activities is that these enzymes allow the alginate structures to be tailored to different layers of the cyst under diverse environmental conditions. For example, the epimerase AlgE1 has two catalytic domains that introduce primarily MG-blocks and G-blocks, respectively (Ertesvåg et al., 1998). Decreasing the availability of $\mathrm{Ca}^{2+}$ in the presence of $\mathrm{AlgE1}$ in vitro led to greater incorporation of G-blocks into polyM alginate. This may provide a means in vivo to maintain the strength of $\mathrm{Ca}^{2+}$-mediated inter-alginate bonds in the face of decreased environmental $\mathrm{Ca}^{2+}$ availability (Ertesvåg et al., 1998). Regulation of alginate structure is also observed during vegetative growth of $A$. vinelandii, where nitrogen fixation is mediated by the expression of highly oxygen-sensitive nitrogenases. In this state, alginate is utilized as a barrier to prevent the diffusion of oxygen into the cell. In the presence of increasing environmental $\mathrm{O}_{2}$ concentrations, $A$. vinelandii was able to produce alginate with greater G-content, which led to the formation of a thicker, denser alginate layer around the cell and thus limited oxygen penetration (Sabra et al., 2000). The expression of different mannuronan C5-epimerases is also regulated over the course of the $A$. vinelandii life cycle, including during vegetative growth, cyst development, and cyst germination (Høidal et al., 2000). Although the exact biological function for the expression of specific epimerases at unique points in the life cycle of A. vinelandii has not been determined, preferential expression of AlgE7 during cyst germination could be linked to the apparent lyase activity of this enzyme, which may be utilized to degrade the cyst coat (Høidal et al., 2000).

Unlike AlgG in P. aeruginosa, the importance of the AlgE17 epimerases in the formation of the cyst coat and tolerance to desiccation has been explored. Inactivation of the AlgE1-7 epimerases, either through chromosomal deletion in A. vinelandii (Steigedal et al., 2008) or by inactivating the Type 1 secretion system responsible for their export (Gimmestad et al., 2006) led to the production of low G-content alginate, suggesting that the periplasmic $A$. vinelandii $\mathrm{AlgG}$ is active but not very efficient. In both cases, these mutants were unable to form a cyst coat and could not survive desiccation. In contrast, deletion of individual $\operatorname{alg} E$ genes, with the exception of $\operatorname{algE3}$, did not have an appreciable effect on the G-content of alginate. Deletion of algE3 showed a significant reduction in G-content (Steigedal et al., 2008). However, since each of the individual $\operatorname{alg} E$ deletion mutants was able to form a functional cyst and survive desiccation, it appears that no single epimerase is absolutely essential for cyst formation or germination. This suggests that the presence of multiple extracellular epimerases may increase redundancy of epimerase activity to ensure formation of a functional cyst coat (Steigedal et al., 2008). It remains to be determined whether cyst formation under unique stressful conditions may require specific epimerases, and little work has been done to date to examine the role of mannuronan $\mathrm{C} 5$ epimerases during the vegetative stage of $A$. vinelandii growth.

While a great deal is understood about the regulation of alginate biosynthesis and its modification at the genetic and protein level (Hay et al., 2014), the implications of alginate acetylation and epimerization in terms of biofilm formation, pathogenicity and virulence, environmental adaptability and survivability remain largely uncharacterized.

\section{The Pel Polysaccharide}

In addition to alginate, $P$. aeruginosa is capable of synthesizing two other polymers that have been implicated in biofilm formation, the Pel and Psl polysaccharides (PEL and PSL; Franklin et al., 2011). Unlike alginate, PEL and PSL are primarily associated with the establishment of non-mucoid biofilms. PSL is a neutral, branched polysaccharide with a five-sugar repeat unit composed of D-mannose, D-glucose, and L-rhamnose and is not thought to undergo any modifications after polymerization (Byrd et al., 2009). The exact structure of PEL is currently unknown, but it is predicted to be glucose rich (Friedman and Kolter, 2004; Ma et al., 2012). Colvin and colleagues have demonstrated that the PEL biosynthesis protein PelA has deacetylase activity in vitro and when residues predicted to be required for deacetylation were mutated, this activity was lost. Introduction of these PelA deacetylation mutations in $P$. aeruginosa PA14, which uses PEL as the primary EPS, led to a biofilm deficient phenotype and a lack of material recognizable by PEL-reactive antisera (Table 1; Colvin et al., 2013). Given the localization of PelA to the periplasm (Colvin et al., 2013), deacetylation of PEL following polymerization may be necessary for biofilm formation, and suggests that an acetylated sugar is likely a feature of the PEL. Our current understanding of PEL biosynthesis is limited, and it remains to be determined whether PelA acts directly on PEL, the degree of PEL deacetylation by PelA, and what effect this modification has on virulence.

\section{Cepacian}

The Bcc is a group of at least 17 different bacterial species, including beneficial environmental isolates, as well as rhizosphere parasites, and plant and animal pathogens (Mahenthiralingam et al., 2002; Vanlaere et al., 2009). The Bcc have become increasingly important as opportunistic pathogens of immunocompromised individuals and those with CF (Mahenthiralingam et al., 2005). In CF patients, Bcc infections occasionally develop into a form of necrotising pneumonia, known as cepacia syndrome, which often leads to patient death (Govan and Deretic, 1996). The majority of both clinical and environmental Bcc isolates produce the EPS cepacian (Ferreira et al., 2010); a known virulence factor that contributes significantly to bacterial pathogenicity. Cepacian is composed of glucose, GlcA, mannose, rhamnose, and galactose in a 1:1:1:1:3 ratio and is decorated with acetyl groups (Figure 4; Cérantola et al., 1999; Cescutti et al., 2000; Linker et al., 2001). The acetyl groups can be found at 12 different locations on the polymer repeating unit with an average of three acetyl groups present per repeat unit (Cescutti et al., 2011). The genes responsible for cepacian acetylation were discovered by Ferreira and colleagues, and include the putative acetyltransferases $b c e O, b c e S$, and $b c e U$ (Ferreira et al., 2010). Mutations in bceS produced cepacian with 


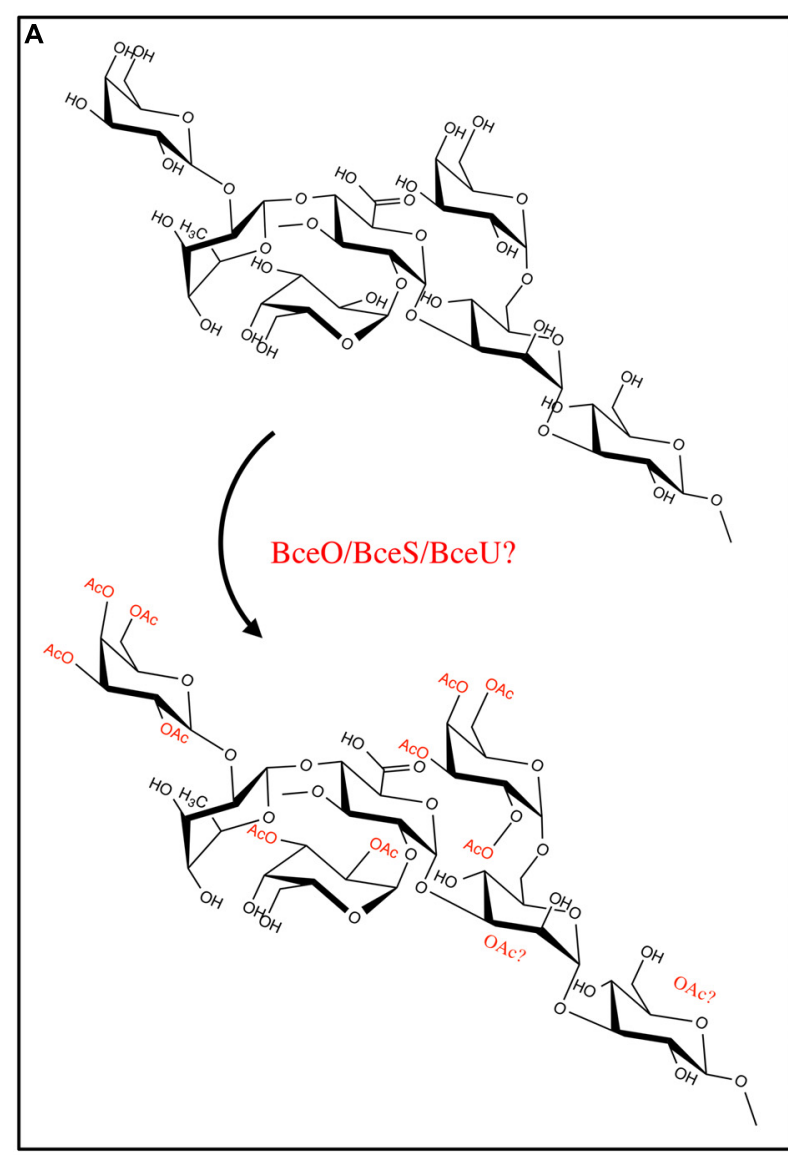

FIGURE 4 | Cepacian modifications and biosynthetic apparatus. Not to scale. (A) Cepacian may be $\mathrm{O}$-acetylated at various locations by BceOSU, leading to a number of unique combinations with an average of three acetyls per repeat unit. (B) Cepacian repeat units are synthesized in the cytoplasm on an isoprenoid lipid carrier (black circle/gray circle), initiated by BceB and continued by glycosyltransferases BceGHJKR. BceGHR are cytoplasmic, while BceJK are integral membrane proteins. BceOSU are predicted to be membrane embedded acetyltransferases that decorate the repeat unit with acetyl groups. BceQ

translocates the repeat units across the inner membrane, followed by addition

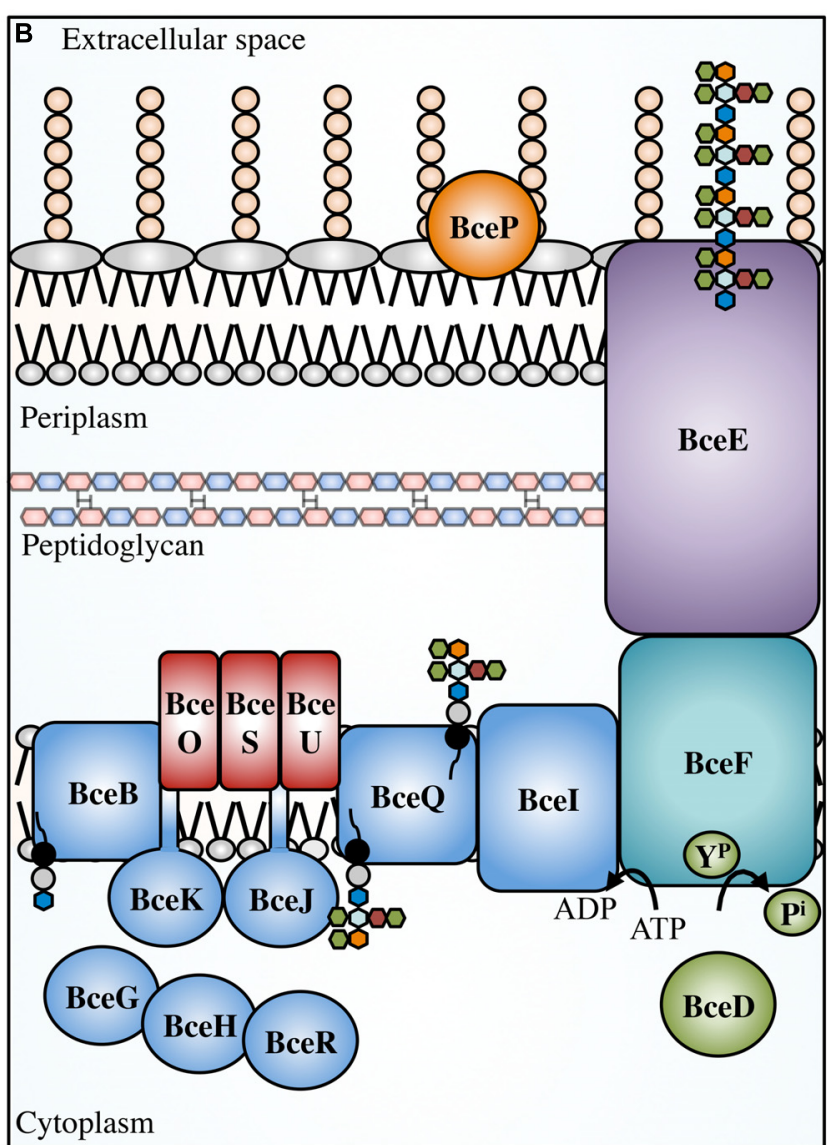

of repeat units to the growing polymer at the periplasmic side, which is dependent on Bcel. Polymerization and export requires BceF, a tyrosine kinase. $\mathrm{BceD}$ is a protein tyrosine phosphatase which dephosphorylates BceF. BceE is the channel for polymer export across the OM. BceP is putatively involved in polysaccharide degradation, though its role and localization is unkonwn. ATP, adenosine- $5^{\prime}$-triphosphate; ADP, adenosine- $5^{\prime}$-diphosphate; $Y^{P}$, phosphorylated tyrosine residue; $\mathrm{P}^{\mathrm{i}}$, inorganic phosphate. Green hexagon, galactose; orange hexagon, GlcA; light blue hexagon, mannose; maroon hexagon, rhamnose; blue hexagon, glucose. approximately $20 \%$ fewer acetyl groups, implicating this protein in partial cepacian acetylation (Ferreira et al., 2010). The roles of bceO and bce $U$ in cepacian acetylation have not been evaluated, nor has a triple mutant been generated to discern the fitness of an acetyl-deficient cepacian producer.

An enzyme with lyase activity that specifically degrades cepacian has been isolated from culture supernatants of Bacillus sp. This enzyme has significantly higher activity against the chemically deacetylated polymer than native cepacian, implicating acetylation in protective mechanisms (Table 2; Cescutti et al., 2006). As with alginate acetylation, cepacian acetylation may have evolved as a defensive mechanism to prevent polymer cleavage in the presence of competitive organisms. Furthermore, like alginate, cepacian acetyl groups have been shown to provide protection against ROS, specifically hypochlorite (Cuzzi et al., 2012). Acetyl groups were the first structural features to undergo damage following hypochlorite treatment, which led to a loss of polymer-polymer interactions and cepacian unfolding, increasing the susceptibility of the cepacian backbone to hypochlorite degradation (Cuzzi et al., 2012). Consequently, cepacian acetylation improves polymer robustness to hypochlorite-mediated damage and increases the amount of polymer reactive groups that could neutralize hypochlorite prior to reaching the cellular surface. Further study of cepacian producing Bcc pathogens is necessary to determine, whether like alginate, there is a role for cepacian acetyl modification in immune evasion.

\section{Vibrio Polysaccharide (VPS)}

Vibrio cholerae is a human pathogen that causes the diarrhoeal disease cholera (Kaper et al., 1995; Faruque et al., 1998). This bacterium is a natural inhabitant of aquatic ecosystems, where 
it forms biofilms on a variety of surfaces, including plankton, plants, crustaceans, insects, and sediment (Huq et al., 1983, 1995; Halpern et al., 2004; Broza et al., 2005). In areas where cholera is endemic, $V$. cholerae has been shown to form suspended biofilm-like aggregates in surface waters, however, when particles $>20 \mu \mathrm{m}$ in diameter are removed from water sources, the incidence of cholera can be reduced (Huq et al., 1996; Colwell et al., 2003). Furthermore, it has been shown that the average infectivity of the aggregate form of $V$. cholerae is significantly higher than that of planktonic cells (Faruque et al., 2006), and biofilm formation within aquatic ecosystems significantly improves V. cholerae fitness and persistence (Matz et al., 2005). A major component of the biofilm produced by $V$. cholerae is an EPS called VPS. This polymer is thought to be produced during infection and contributes to bacterial colonization and survival (Yildiz and Schoolnik, 1999; Fong et al., 2010). The chemical structure of VPS revealed a backbone containing the unusual constituent GulNAcAGly: the amide formed from 2-acetamido-2-deoxy-L-guluronic acid and glycine (Figure 6; Yildiz et al., 2014). Of the genes involved in VPS biosynthesis, originally identified using a transposon mutagenesis screen (Yildiz and Schoolnik, 1999), two putative acetyltransferases, $v p s G$ and $v p s C$, were identified (Fong et al., 2010). Deletion of $v p s G$ results in reduced biofilm formation and altered biofilmrelated phenotypes, as well as weak reactivity with VPS antisera, suggesting that it may modify the polymer, perhaps through acetylation (Table 1). In contrast, deletions of $v p s C$ do not affect biofilm formation or VPS production, suggesting that $v p s C$ is inactive, not expressed, or is performing some other function in VPS biosynthesis besides polymer modification (Fong et al., 2010). The chemical composition of VPS produced by $v p s G$ and $v p s C$ mutants was not studied for alterations in acetyl content. The presence of GulNAcA in VPS may be the result of epimerization by the predicted GDP-mannose dehydrogenase $\mathrm{VpsB}$, a conversion similar to the ManA to GulA epimerization catalyzed by AlgG in the biosynthesis of alginate by $P$. aeruginosa (Wolfram et al., 2014; Yildiz et al., 2014). The unusual glycine modification in VPS requires further exploration, as the enzyme responsible for its addition is presently unknown. Given the important role of VPS in $V$. cholerae pathogenesis and environmental persistence, and the recent determination of its precise chemical structure, we anticipate that the proteins involved in VPS modification will soon be identified and characterized.

\section{Glycosaminoglycans (GAGs)}

GAGs are a group of polymers that are typically composed of a disaccharide repeat unit containing an amino sugar and a hexuronic acid (Laurent and Fraser, 1992; Esko and Lindahl, 2001; DeAngelis, 2002; Silbert and Sugumaran, 2002). GAGs were initially thought to exist only in the animal kingdom, where they serve essential biological functions, however, there has been an emergence of GAG-like polymers amongst prokaryotes (Vann et al., 1981; Rodriguez et al., 1988; DeAngelis et al., 2002). Prokaryotic GAGs are typically less complex than their eukaryotic counterparts due to an absence of modifications such as sulfation (Raedts et al., 2011). HS, for example, is an essential GAG in animals and is composed of repeating disaccharides of GlcA and GlcNAc (Kjellén and Lindahl, 1991). HS can be modified post-polymerization by a glucuronyl C5-epimerase, which converts GlcA to IdoA, as well as by the addition of sulfate groups to GlcNAc or IdoA moieties. Mouse embryos lacking the GlcA C5-epimerase display a lethal phenotype characterized by skeletal malformations and lung defects (Li et al., 2003), highlighting the importance of HS epimerization in murine development. Interestingly, the K5 antigen of E. coli O10:K5:H4 has an identical structure to heparosan, the unsulfated, nonepimerized backbone structure of HS (Vann et al., 1981). K5 heparosan is a form of molecular camouflage, as it imparts low immunogenicity to the bacterium in humans and hence increased pathogenicity (Vann et al., 1981).

Although sulfation has not yet been observed amongst prokaryotic GAGs, IdoA residues have been found to be constituents of bacterial GAGs (Figure 6). The identification of the bacteria glucuronyl $\mathrm{C} 5$-epimerase has proven elusive (Raedts et al., 2011), however, an enzyme (RED65_08024) from the marine bacterium Bermanella marisrubi that shares $37 \%$ sequence similarity with the human glucuronyl C5-epimerase has been characterized and shown in vitro to convert GlcA to IdoA in de-sulfated mouse HS (Raedts et al., 2013). This glucuronyl C5-epimerase represents the first prokaryotic protein capable of generating IdoA residues, and is the only identified epimerase that can function on bacterial polysaccharides postpolymerization, besides AlgG and AlgE1-7. Unfortunately, the EPS produced by B. marisrubi has not been characterized, so its target remains unknown. Nevertheless, the ability of bacteria to more closely replicate the structures of essential human polysaccharides by expression of homologous modification enzymes likely serves as a mechanism to mask their presence from the host immune system (Cress et al., 2014).

\section{Poly- $\beta-1,6-N$-Acetyl-glucosamine (PNAG)}

Poly- $\beta-1,6-N$-acetyl-glucosamine is a poly-GlcNAc polymer that is produced by a wide range of Gram-positive and Gram-negative bacterial pathogens, including Staphylococcus epidermidis, Staphylococcus aureus, Escherichia coli, Yersinia pestis, Bordetella sp., Acinetobacter baumanii, Actinobacillus pleuropneumoniae, Burkholderia cepacia complex (Bcc), and Aggregatibacter actinomycetemcomitans (Cramton et al., 1999; Vuong et al., 2004b; Wang et al., 2004; Izano et al., 2007, 2008; Parise et al., 2007; Bobrov et al., 2008; Choi et al., 2009). These organisms are responsible for a wide spectrum of diseases, including but not limited to, hospital acquired infections, toxic shock syndrome, plague, and whooping cough. Depending on the source or organism in question, PNAG may also be referred to as PGA (polyglucosamine, in Gram-negative bacteria), PIA (in Gram-positive bacteria), poly-NAG, hms+ (in Y. pestis), or BPS (Bordetella polysaccharide, in Bordetella sp.). Given the differences in PNAG modifications between Gram-positive and 
Gram-negative bacteria, as described below, we will use PGA and PIA to refer to PNAG polymer produced by Gram-negative and Gram-positive organisms, respectively.

Initially $S$. epidermidis was thought to produce several different polymers, but the discovery of the icaADBC operon (Heilmann et al., 1996a,b; Gerke et al., 1998) revealed that only a single polymer, PIA, was produced (Tojo et al., 1988; Christensen et al., 1990; Heilmann et al., 1996a; Mack et al., 1996; McKenney et al., 1998). PIA is a partially deacetylated $\beta-1,6-$ GlcNAc polymer. In $S$. epidermidis and S. aureus 15$20 \%$ of the $N$-acetyls are removed by the extracellular, cellsurface associated polysaccharide deacetylase IcaB (Table 1; Figure 5; Vuong et al., 2004a; Cerca et al., 2007). In addition to deacetylation, approximately 6 and $10 \%$ of GlcNAc residues in $S$ epidermidis and $S$. aureus, respectively, are $O$-succinylated (Joyce et al., 2003; Sadovskaya et al., 2005). This modification is thought to be performed by the membrane localized protein, IcaC (Atkin et al., 2014). Interestingly, a mechanism of phase variation, where bacteria modulate virulence phenotypes at the genome level in a rapid on/off fashion, was noted in $S$. aureus wherein slipped-strand mispairing led to inactivation of icaC (Brooks and Jefferson, 2014). This phenotype confers a fitness advantage that was not seen when the ica operon was deleted, which may be a response to modulate PIA $O$-succinylation and thus decrease the overall anionic charge of the polymer.

The production of PGA has been extensively characterized in $E$. coli, where the pgaABCD operon encodes the proteins necessary for its biosynthesis (Wang et al., 2004). In E. coli,

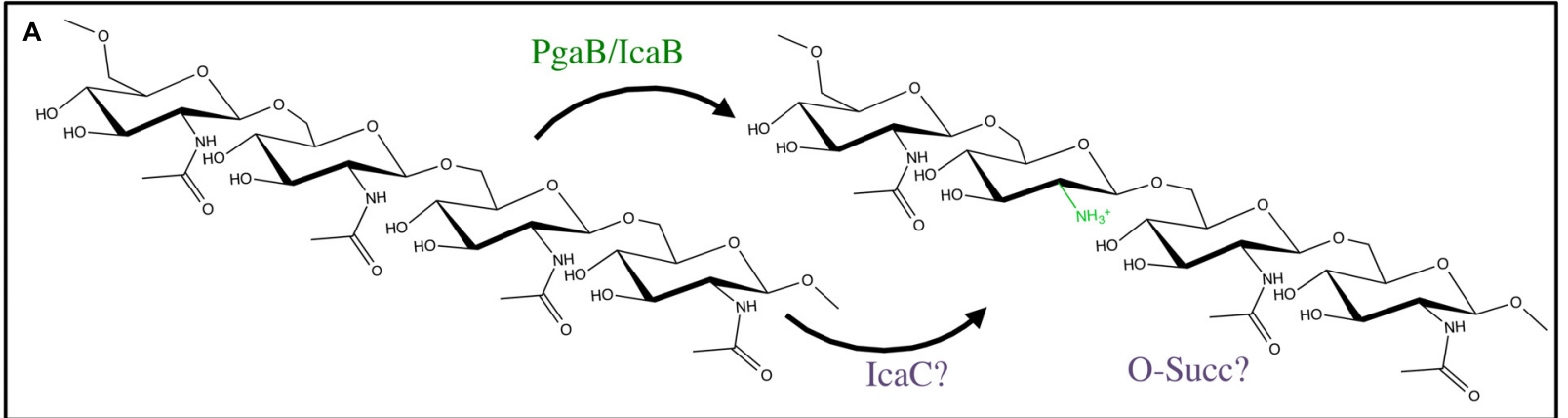

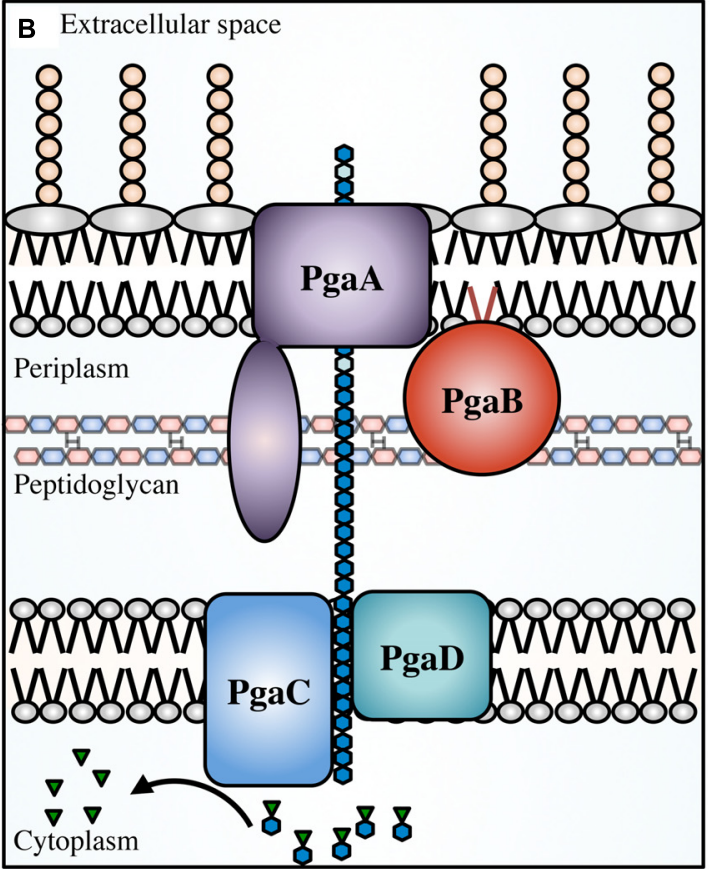

FIGURE 5 | The PNAG and PIA modifications and biosynthetic apparatus. Not to scale. (A) PNAG polymers are partially deacetylated by PgaB in Escherichia coli, or IcaB in Staphylococcal species. It has been proposed that IcaC O-succinylates the polymer in certain Staphylococcal species, however, the location of the succinyl groups and the order of deacetylation/succinylation has not yet been determined. The proteins involved in PNAG biosynthesis in E. coli (B), and PIA synthesis in Staphylococcal species

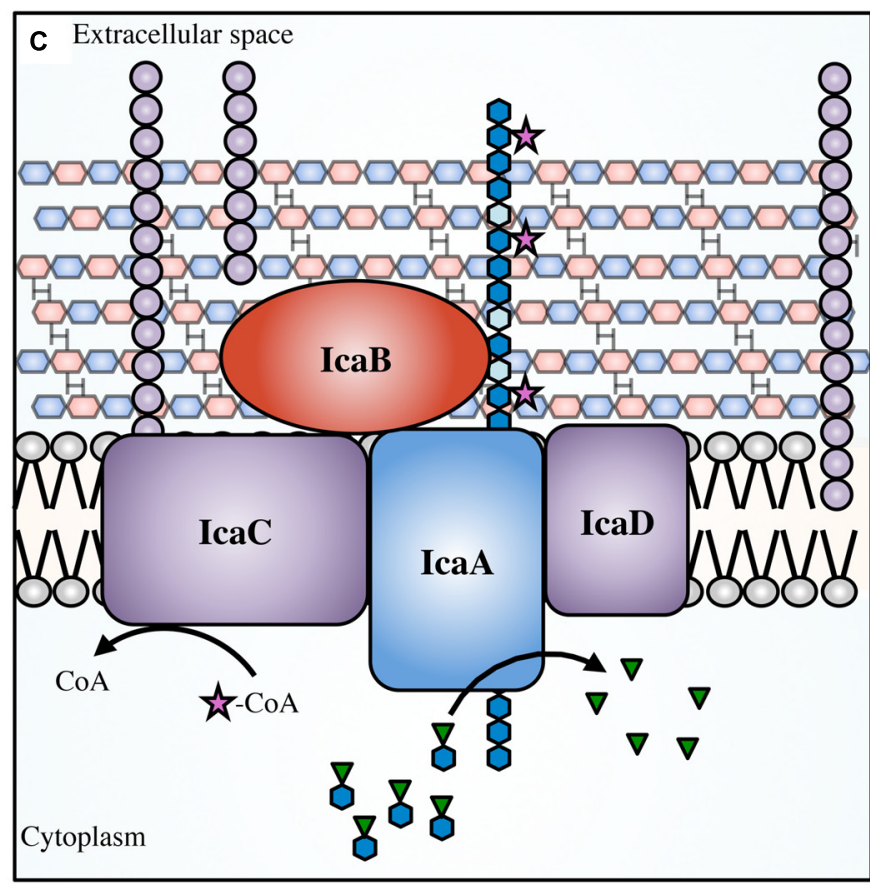

(C). PNAG (blue hexagon chain) is synthesized in the cytoplasm from the nucleotide-sugar precursor UDP-GlcNAc (blue hexagons with green inverted triangles). The polymer is transported across the inner membrane via PgaCD, deacetylated (light blue hexagons) by PgaB in the periplasm, and then exported through the PgaA porin. PIA is transported across the cytoplasmic membrane by IcaAD, then partially deacetylated by IcaB in the extracellular space. PIA has been proposed to be $\mathrm{O}$-succinylated by IcaC (magenta star). 


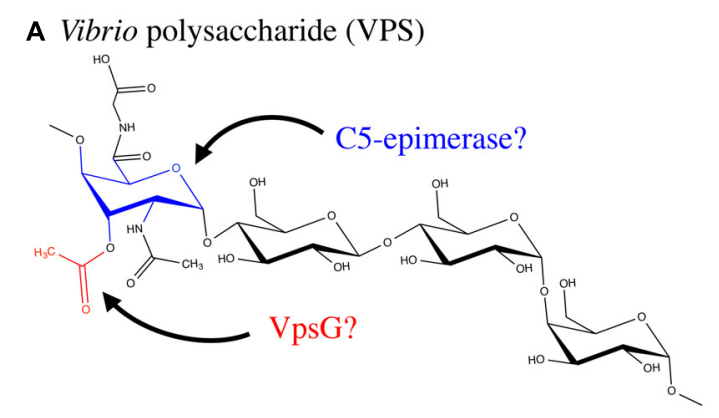

FIGURE 6 | Exopolysaccharide modifications of VPS and Heparosan. (A) VPS is produced by Vibrio cholerae O1 El Tor and contains an O-acetyl group, likely added by VpsG. In addition the polymer has a glycine modification and an $\mathrm{N}$-acetyl group; the enzymes responsible for these modifications have not been determined. VPS contains a GulA residue which is epimerized by an

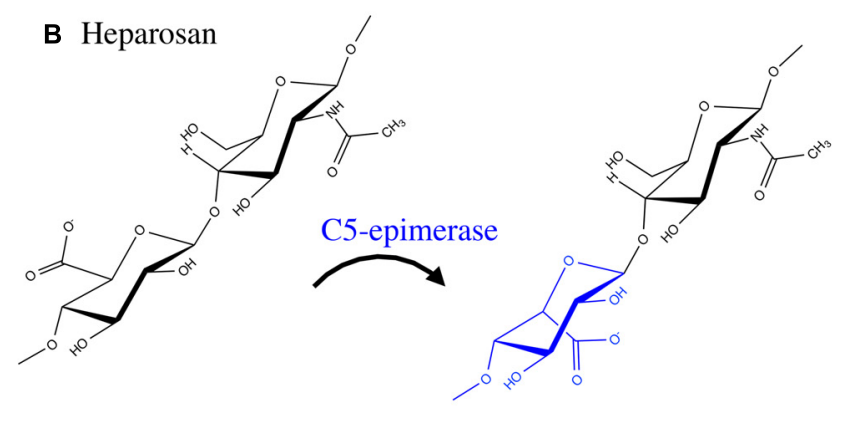

unknown C5-epimerase. (B) Heparosan, a GAG composed of a disaccharide repeating unit of GlcA and GlcNAc, produced by select bacteria such as the urinary tract pathogen E. coli O10:K5:H4. A C5-epimerase introduces IdoA residues. The proteins involved in, and mechanism of, biosynthesis of the above EPS have not been fully resolved. approximately $3-5 \%$ of $N$-acetyls are removed by the lipoprotein PgaB (Wang et al., 2004; Itoh et al., 2008; Little et al., 2012). The $\mathrm{N}$-terminal domain of PgaB is homologous to IcaB in Grampositive bacteria but the protein is located on the inner leaflet of the outer membrane. There is no IcaC ortholog in the pgaABCD operon, which is consistent with an observed lack of $O$-succinyl groups in PGA.

Partial deacetylation of PNAG by both $\mathrm{IcaB}$ and PgaB is important for a variety of biofilm-associated phenotypes in S. epidermidis, S. aureus, and E. coli. Deletion of icaB in $S$. epidermidis led to the production of fully acetylated PIA, suggesting that IcaB is not necessary for polymer production (Vuong et al., 2004a). However, the fully acetylated polymer was not retained at the cellular surface and was shed into the culture media, which led to deficiencies in biofilm formation and surface attachment (Table 2). The lack of deacetylation led to a loss of cationic charge in the polymer, which may be essential for interactions with the anionic cell surface of S. epidermidis (Vuong et al., 2004a). Furthermore, icaBdeficient mutants of $S$. epidermidis were more susceptible to human cationic antimicrobial peptides and phagocytosis by neutrophils, and were unable to persist in a mouse model of device-related infections (Vuong et al., 2004a). Deletion of $i c a B$ in $S$. aureus produced similar phenotypes (Cerca et al., 2007). Intriguingly, the production of wall teichoic acids, the predominant anionic component of the Gram-positive bacterial envelope, was dispensable for adherence of PIA to the cell surface of S. aureus (Vergara-Irigaray et al., 2008), suggesting that other less prevalent anionic species mediate this interaction.

In contrast to IcaB, inactivation of PgaB in E. coli prevented polymer export, suggesting that partial deacetylation is necessary for export through the predicted outer membrane porin PgaA (Itoh et al., 2008). This is in line with findings that suggest conformational changes in the C-terminal domain of PgaB, upon binding of deacetylated PNAG, assist in targeting PNAG for export (Little et al., 2014b). Deacetylation has also been studied in Y. pestis, where a PNAG-like polymer is thought to mediate biofilm formation. Biofilm formation in Y. pestis is crucial for its zoonotic transmission (Jarrett et al., 2004). In the flea, the proventriculus, a feeding tube covered in spines that connects the midgut to the esophagus, provides a platform for the adhesion of $Y$. pestis aggregates. Subsequent colonization impedes blood passage and leads to transposition of $Y$. pestis from flea to mammal when a flea attempts excessive feeding due to a partial or completely blocked proventriculus (Jarrett et al., 2004). The hmsHFRS operon in $Y$. pestis is orthologous to the pgaABCD operon, where $\mathrm{HmsF}$ is the outer membrane localized deacetylase with structural similarity to PgaB (Forman et al., 2006). Mutation or deletion of $h m s F$ led to a deficiency in biofilm formation. This suggests $\mathrm{HmsF}$ in $Y$. pestis may be analogous to PgaB in E. coli in terms of de- $N$-acetylation activity and importance for polysaccharide export and biofilm formation.

While PNAG production has been studied primarily in $S$. aureus, S. epidermidis, and E. coli, there are a multitude of additional pathogenic bacteria, fungi, and protozoans that may produce this polymer (Cywes-Bentley et al., 2013). PNAG could represent the first example of an EPS that is broadly utilized by pathogenic organisms as a mechanism to improve fitness in the environment or during infection.

\section{Insights from Modification of Other Microbial Polysaccharides}

The implications of EPS modifications in pathogenic bacteria have been studied to some extent, particularly in alginate and PNAG producing bacteria (Figure 2; Table 2). However, the breadth of our knowledge in this field remains limited. Despite this, comparable modifications found on LPS and CPSs have been studied extensively in an effort to identify vaccine targets, and can be used for comparison purposes to generate new hypotheses regarding EPS modifications (Cody et al., 2003; Pinto and Berti, 2014). In particular, the study of polysaccharide acetyl modifications has clarified their role in mediating a variety of survival mechanisms.

Many of the protective benefits of EPS acetyl modifications described above have been noted for other bacterial pathogens. 
For instance, in Haemophilus influenzae, an opportunistic pathogen of the upper respiratory tract, acetylation of LPS by the acetyltransferase OafA leads to increased resistance to complement-mediated killing by human serum (Fox et al., 2005). Similarly, in S. aureus, the acetyltransferase Cap5H, which is responsible for the $\mathrm{O}$-acetylation of type $5 \mathrm{CPS}$, confers protection against opsonophagocytic killing and improves propagation in a murine model of infection (Bhasin et al., 1998). Type 5 CPS producers also exhibit increased survival rates in murine models of bacteremia and renal abscess formation and resistance to killing in whole mouse blood and opsonophagocytic assays, in comparison to producers of the structurally similar type $8 \mathrm{CPS}$ which have reduced levels of $\mathrm{N}$-acetylation (Watts et al., 2005). Beyond the prokaryotic domain, acetyl modifications are also incorporated into the CPS of the pathogenic fungus Cryptococcus neoformans to evade complement activation (Fujihara et al., 1997), decrease the efficiency of capsule clearance by the host (Kozel et al., 2003), and inhibit neutrophil migration (Ellerbroek et al., 2004) during cryptococcosis. An excellent example of the benefits of polysaccharide acetyl modifications comes from a survey of clinical isolates of Streptococcus pneumoniae and E. coli $\mathrm{K} 1$, which found that the bacteria expressing acetyl-decorated polymers were more virulent and invasive than those that expressed polymers lacking the modification (Frasa et al., 1993; Melin et al., 2010). Therefore, the immunomodulatory characteristics of acetyl modifications are utilized by a wide range of pathogenic organisms and likely represent a general mechanism for survival and proliferation within the host.

The above notion is firmly supported by studies of serotype variation within the context of CPS biosynthesis. In Streptococcus pneumoniae, a causative agent of meningitis, bacteremia, and pneumonia, there are more than 90 different capsule serotypes with unique carbohydrate structures and biosynthetic loci. This has evolved, in part, as a mechanism to overcome serotype-specific host mechanisms of adaptive immunity that can efficiently clear infections. In some serotypes, such as $9 \mathrm{~V} / 9 \mathrm{~A}$, $11 \mathrm{~A} / 11 \mathrm{E}$, and $15 \mathrm{~B} / 15 \mathrm{C}$, the CPS structures differ only in the degree of $O$-acetylation (Jansson et al., 1987; Rutherford et al., 1991; Zartler et al., 2009). Mechanisms within S. pneumoniae have been revealed that allow for serotype switching during infection as a means to actively evade the host immune response. In the case of serotypes $9 \mathrm{~V}$ and $11 \mathrm{~A}$, inactivating mutations in the acetyltransferase-encoding gene $w c e J$ led to expression of nonacetylated 9A and 11E capsule (Calix and Nahm, 2010; Calix et al., 2011). Moreover, certain wceJ mutations only partially inhibit acetyltransferase activity, which have led to intermediate 9V/9A and $11 \mathrm{~A} / 11 \mathrm{E}$ phenotypes (Calix et al., 2011, 2014). In the case of $15 \mathrm{~B} / 15 \mathrm{C}$ serotype switching, the process is reversible due to slipped-strand mispairing of the acetyltransferase-encoding gene wciZ (van Selm et al., 2003). Regardless of the mechanism, this mid-infection serotype variation provides significant protective advantages to $S$. pneumoniae in terms of antibody evasion. For example, antibodies generated against $O$-acetylated serotype $15 \mathrm{~B}$ were unreactive with non-acetylated $15 \mathrm{C}$ polymer (Rajam et al., 2007), and serotype 9V specific antibodies exhibited reduced specificity for 9A polymer (Calix et al., 2012). Furthermore,
$10-20 \%$ of individuals receiving a S. pneumoniae vaccine targeted against the $9 \mathrm{~V}$ polysaccharide did not generate antibodies targeting serotype 9A (McNeely et al., 1998). In addition, the ability of acetyl groups to mask protective epitopes of bacterial polysaccharides has been noted for the Vi antigen of Salmonella typhi (Szu et al., 1991), Salmonella typhimurium O-antigen (Kim and Slauch, 1999) and Neisseria meningitidis serogroup A, C, and Y CPS (Michon et al., 2000; Berry et al., 2002; Fusco et al., 2007). Therefore, through modulation of acetyl groups on the polymer, a wide variety of pathogenic bacteria are able to evade host-mediated mechanisms of adaptive immunity.

The above examples illustrate scenarios in which acetyl modification is an all-or-nothing response to adaptive immunity, however, in the case of GBS, acetyl levels on its sialic acid CPS can be fine-tuned by the actions of the acetyltransferase NeuD and the acetylesterase NeuA (Lewis et al., 2006, 2007). Different degrees of $O$-acetylation in GBS CPS have been linked to different stages of invasion and infection. For instance, it is thought that during the asymptomatic stages of initial colonization and persistence in the human gastrointestinal and vaginal tracts, GBS produces an extensively acetylated form of CPS to protect against degradation by sialidases introduced by competing microbes in these environments (Weiman et al., 2009). However, highly acetylated CPS renders GBS more susceptible to killing by neutrophils and reduces virulence during stages of opportunistic infections (Weiman et al., 2010). Therefore, during infection it is thought that GBS produces a sparsely acetylated form of CPS that improves resistance to neutrophil-mediated killing through reduced neutrophil activation and production of proinflammatory cytokines, and enhances survival in the murine bladder (Kline et al., 2011). Interestingly, this variant of CPS is also able to promote the persistence of uropathogenic E. coli in co-culture urinary tract infection models (Kline et al., 2012). Therefore, in certain pathogens, specific degrees of polysaccharide acetylation allow for adaptation during different stages of colonization and infection.

The above examples of acetyl modulation in LPS and CPS not only reinforce the importance of EPS acetylation for pathogenicity and persistence, but also provide additional perspectives in considering the variability of this modification observed in alginate and cepacian. For instance, cepacian has on average three acetyl groups per repeat unit, each located on one of 12 potential positions (Cescutti et al., 2011). Therefore, each cepacian repeat unit can have one or more acetyl groups at any of 12 positions, generating an overwhelming number of unique acetyl decoration patterns. Given the importance of acetyl groups in forming or masking antibody epitopes, this level of diversity would make the generation of protective antibodies or the development of an effective vaccine extraordinarily difficult. Furthermore, production of such a heterogeneous polymer likely requires an arsenal of regulatory factors and/or acetyltransferases, very few of which have been discovered in the context of cepacian biosynthesis (Ferreira et al., 2011). Similar to S. pneumoniae and N. meningitidis CPS production, members of the Bcc may modulate the presentation of cepacian acetyl groups through an as yet unknown mechanism as a means to evade host adaptive immune mechanisms. 
The degree of acetylation and epimerization of alginate has long been known to differ depending on the organism and strain, as well as the composition of the growth medium (Day, 1988; Marty et al., 1992; Peña et al., 2006). This reflects, in part, a need to adapt to the specific conditions imposed by different nutritional media, and may mirror other features of the environment from which the organism was isolated. In line with this concept, additional promoters within the alginate operon have been identified upstream of algG and algIJF in P. aeruginosa, suggesting that there may be modes of regulating the levels of these modifying enzymes independently of the rest of the alginate biosynthesis machinery (Paletta and Ohman, 2012). The upregulation of $\mathrm{O}$-acetylation machinery would not only increase alginate acetyl content, but would also decrease the availability of substrate for AlgG and thus decrease epimerization levels. Conversely, upregulation of algG would increase the number of G-residues that cannot act as substrates for $O$-acetylation. Therefore, there is the potential for a complicated regulatory interplay between these processes, much like the reciprocal $O$-acetylation/de-O-acetylation of GBS CPS that allows for finetuning of acetyl levels at different stages of infection.

The degree of PNAG de- $N$-acetylation is not known to vary considerably, and the exact processes involved in VPS acetylation and epimerization, PIA O-succinylation, PEL deacetylation and GAG epimerization are poorly understood. However, the ability to perform these types of modifications in a random fashion may increase the difficulty in generating antibodies that recognize specific epitopes on these EPS, either during host adaptive immune responses or in vaccine development (Gening et al., 2010). As such, EPS modifications are capable of imparting beneficial characteristics upon polymers that improve persistence, survival, or evasion of the immune response in their cognate bacteria regardless of their frequency, mechanism of addition to the polymer, or chemical properties.

\section{Reflection and Future Perspectives}

Identifying and characterizing biofilm EPS is difficult and there are a number of hurdles that need to be overcome. One of the initial challenges involves culturing biofilm-forming bacteria. Identification of an appropriate medium and growth conditions is required to study EPS production of certain microorganisms in the laboratory (Stewart, 2012). Of those that can be cultured, it is imperative to use similar growth conditions when making experimental comparisons in the literature, as variations can affect the presence or degree of different polysaccharide modifications. With alginate, varying levels of acetylation and epimerization are observed depending on the culture conditions, as well as varying biofilm phenotypes of identical P. aeruginosa strains (Pier et al., 2001; Tielen et al., 2005). Additionally, conflicting studies on the levels of pyruvyl and $O$-acetyl modifications to xanthan gum were attributed to different media conditions (Bradshaw et al., 1983). Different media or culturing equipment may also affect experiments such as surface attachment assays. For example, different types of plastics were found to affect PIA-mediated surface attachment in microtitre plates (Maira-Litràn et al., 2004). This suggests that during preliminary analyses, multiple types of media and different materials including plastics and glass should be tested to ensure the validity of observed biofilm phenotypes. Variations in the abundance or type of modifications on a given polymer under different experimental conditions can be difficult to quantify; however, this variation likely reflects the ability of different bacteria to adapt to unique situations. Many EPS-producing bacteria naturally exist in diverse environments and are also able to infect various hosts and survive in specific tissues. Additionally, during the course of infection, the environment within the host will change as immune mechanisms attempt to eradicate the bacteria and the surrounding tissue suffers damage. Variations in the degree of modifications under different growth conditions or stressors may therefore provide valuable insight into bacterial adaptation.

The majority of biofilm studies focusing on EPS modifications have been performed using in vitro model systems with monospecies cultures. However, the majority of biofilms from chronic infections differ significantly from those studied in the laboratory (Bjarnsholt et al., 2013a). One significant issue lies in the use of abiotic surfaces, such as cover slides or the plastic surfaces of 96-well plates for the growth and study of biofilms. While some systems can closely approximate the conditions encountered in vivo, such as flow cell models for catheter associated infections, biofilms from infections like CF pneumonia or those encountered in epidermal wounds are thought to involve attachment to host cells or host-derived molecules (Bjarnsholt et al., 2009). In these instances it is challenging to extrapolate results obtained in vitro to chronic biofilm infections, as modifications that appear important for attachment to abiotic surfaces may be disposable for attachment to host tissues, or vice versa (Leuck et al., 2014). Furthermore, many biofilms encountered in the clinic are not comprised of a single species of bacteria, but rather contain mixtures that can include pathogenic or non-pathogenic bacteria of host or environmental origin, as well as fungi (Wargo and Hogan, 2006; Elias and Banin, 2012). These types of microbial interactions have been studied extensively in the CF lung, where $P$. aeruginosa has been shown to interact with the Bcc opportunistic pathogens B. cepacia and B. cenocepacia (Chattoraj et al., 2010; Schwab et al., 2014), as well as the pathogenic fungus Aspergillus fumigatus (Chotirmall and McElvaney, 2014). In the case of mixed $P$. aeruginosa and $B$. cenocepacia biofilms, the production of alginate by $P$. aeruginosa has been shown to promote $B$. cenocepacia persistence in a mouse model of CF (Chattoraj et al., 2010). This highlights how the production of EPS in mixed species biofilms can have implications that extend beyond the source organism, and suggests that data obtained regarding the presence or absence of EPS modifications in monospecies biofilms in vitro may have additional significance in multispecies biofilms.

Following bacterial culturing, difficulties in polysaccharide isolation due to the compositional complexity of the biofilm matrix or polymer insolubility may necessitate extensive optimization of purification protocols. Typically, separation of the polymer from the cell surface may require the use of procedures that lyse the associated bacteria, introducing 
additional contaminants (Bales et al., 2013). Therefore, it is preferable if possible to isolate EPS from culture supernatants; however, such polymers may exhibit different properties from their cell-associated counterparts leading to discrepant analysis (Maira-Litràn et al., 2002). In either case, once the polymer has been obtained from the cell surface or supernatant, contaminants such as DNA, RNA and protein must be removed. This can be achieved through enzymatic digestion or chemical precipitation of contaminants, or precipitation of EPS. Contaminating carbohydrates can be removed by chromatographic techniques such as size exclusion or ion exchange (Bales et al., 2013). In some cases, purification of EPS leads to insufficient yields for subsequent compositional or structural analysis, often as a result of polymer insolubility. As a result, harsher conditions may need to be employed to solubilize the polymer, including the use of strong acids or bases. During initial structural studies of PIA, strong alkaline purification conditions led to the incorrect identification of $N$-succinyl groups on the polymer (McKenney et al., 1999; Maira-Litràn et al., 2002), which was actually a degradation product of glucosamine monosaccharides (Sadovskaya et al., 2005). Additionally, phosphates have been reported in the monosaccharide composition of polymers, which are occasionally remnants from purification buffers, or teichoic acids in the case of Gram-positive bacteria (Sadovskaya et al., 2005). Harsher conditions can also partially or completely remove functional groups, such as acetyls, or even degrade the polymer, leading to incorrect calculations of molecular weight. The EPS described in this review are the select few whose structures have been determined, or for which we have

\section{References}

Aachmann, F. L., Svanem, B. I. G., Güntert, P., Petersen, S. B., Valla, S., and Wimmer, R. (2006). NMR structure of the R-module: a parallel beta-roll subunit from an Azotobacter vinelandii mannuronan C-5 epimerase. J. Biol. Chem. 281, 7350-7356. doi: 10.1074/jbc.M510069200

Allesen-Holm, M., Barken, K. B., Yang, L., Klausen, M., Webb, J. S., Kjelleberg, S., et al. (2006). A characterization of DNA release in Pseudomonas aeruginosa cultures and biofilms. Mol. Microbiol. 59, 1114-1128. doi: 10.1111/j.13652958.2005.05008.x

Atkin, K. E., Macdonald, S. J., Brentnall, A. S., Potts, J. R., and Thomas, G. H. (2014). A different path: revealing the function of staphylococcal proteins in biofilm formation. FEBS Lett. 588, 1869-1872. doi: 10.1016/j.febslet.2014.04.002

Baker, P., Ricer, T., Moynihan, P. J., Kitova, E. N., Walvoort, M. T. C., Little, D. J., et al. (2014). P. aeruginosa SGNH hydrolase-like proteins AlgJ and AlgX have similar topology but separate and distinct roles in alginate acetylation. PLoS Pathog. 10:e1004334. doi: 10.1371/journal.ppat.1004334

Bales, P. M., Renke, E. M., May, S. L., Shen, Y., and Nelson, D. C. (2013). Purification and characterization of biofilm-associated EPS exopolysaccharides from ESKAPE organisms and other pathogens. PLoS ONE 8:e67950. doi: 10.1371/journal.pone.0067950

Benziman, M., Haigler, C. H., Brown, R. M., White, A. R., and Cooper, K. M. (1980). Cellulose biogenesis: polymerization and crystallization are coupled processes in Acetobacter xylinum. Proc. Natl. Acad. Sci. U.S.A. 77, 6678-6682. doi: 10.1073/pnas.77.11.6678

Berry, D. S., Lynn, F., Lee, C.-H., Frasch, C. E., and Bash, M. C. (2002). Effect of $\mathrm{O}$ acetylation of Neisseria meningitidis serogroup A capsular polysaccharide on development of functional immune responses. Infect. Immun. 70, 3707-3713. doi: 10.1128/IAI.70.7.3707-3713.2002

Bhasin, N., Albus, A., Michon, F., Livolsi, P. J., Park, J. S., and Lee, J. C. (1998). Identification of a gene essential for O-acetylation of the Staphylococcus aureus biochemical and genetic data supporting the importance of the polysaccharide modifications. With improved culturing, purification and structural determination procedures, additional EPS will be discovered and their modifications characterized. We will then be able to formulate trends between different types of modifications and their effect on biofilm formation, pathogenicity, and virulence. Furthermore, the details regarding the genes and proteins involved in the addition of polysaccharide modifications remain largely unavailable. Characterization of these genes and proteins will likely provide details on how the levels and types of modifications are regulated under different conditions. Such findings will have a significant impact on our understanding of bacterial pathogenicity, and may reveal novel drug targets aimed at inhibiting the biosynthesis of these important virulence factors.

\section{Acknowledgments}

The authors thank Drs. Dustin Little, Perrin Baker, and Mark Nitz for their critical reading and contributions to this review. This work was supported by the Canadian Institutes of Health Research Operating Grant 13337 to PLH. GBW is supported by a graduate scholarship from the Natural Sciences and Engineering Research Council of Canada (NSERC). LSM is supported by graduate scholarships from NSERC, the Ontario Graduate Scholarship Program and The Hospital for Sick Children Foundation Student Scholarship Program. PLH is the recipient of a Canada Research Chair.

type 5 capsular polysaccharide. Mol. Microbiol. 27, 9-21. doi: 10.1046/j.13652958.1998.00646.x

Bjarnsholt, T., Alhede, M., Alhede, M., Eickhardt-Sørensen, S. R., Moser, C., Kühl, M., et al. (2013a). The in vivo biofilm. Trends Microbiol. 21, 466-474. doi: 10.1016/j.tim.2013.06.002

Bjarnsholt, T., Ciofu, O., Molin, S., Givskov, M., and Høiby, N. (2013b). Applying insights from biofilm biology to drug development - can a new approach be developed? Nat. Rev. Drug Discov. 12, 791-808. doi: 10.1038/nrd4000

Bjarnsholt, T., Jensen, P. Ø., Fiandaca, M. J., Pedersen, J., Hansen, C. R., Andersen, C. B., et al. (2009). Pseudomonas aeruginosa biofilms in the respiratory tract of cystic fibrosis patients. Pediatr. Pulmonol. 44, 547-558. doi: 10.1002/ppul.21011

Bobrov, A. G., Kirillina, O., Forman, S., Mack, D., and Perry, R. D. (2008). Insights into Yersinia pestis biofilm development: topology and co-interaction of Hms inner membrane proteins involved in exopolysaccharide production. Environ. Microbiol. 10, 1419-1432. doi: 10.1111/j.1462-2920.2007.01554.x

Bradshaw, I. J., Nisbet, B. A., Kerr, M. H., and Sutherland, I. W. (1983). Modified xanthan-its preparation and viscosity. Carbohydr. Polym. 3, 23-38. doi: 10.1016/0144-8617(83)90010-3

Brooks, J. L., and Jefferson, K. K. (2014). Phase variation of poly-Nacetylglucosamine expression in Staphylococcus aureus. PLoS Pathog. 10:e1004292. doi: 10.1371/journal.ppat.1004292

Broza, M., Gancz, H., Halpern, M., and Kashi, Y. (2005). Adult non-biting midges: possible windborne carriers of Vibrio cholerae non-O1 non-O139. Environ. Microbiol. 7, 576-585. doi: 10.1111/j.1462-2920.2005.00745.x

Buchinger, E., Knudsen, D. H., Behrens, M. A., Pedersen, J. S., Aarstad, O. A., Tøndervik, A., et al. (2014). Structural and functional characterization of the R-modules in alginate C-5 epimerases AlgE4 and AlgE6 from Azotobacter vinelandii. J. Biol. Chem. 289, 31382-31396. doi: 10.1074/jbc.M114.567008

Buckmire, F. L. (1984). Influence of nutrient media on the characteristics of the exopolysaccharide produced by three mucoid Pseudomonas aeruginosa strains. Microbios 41, 49-63. 
Bulen, W. A., Burns, R. C., and LeComte, J. R. (1964). Nitrogen fixation: cellfree system with extracts of Azotobacter. Biochem. Biophys. Res. Commun. 17, 265-271. doi: 10.1016/0006-291X(64)90395-X

Byrd, M. S., Sadovskaya, I., Vinogradov, E., Lu, H., Sprinkle, A. B., Richardson, S. H., et al. (2009). Genetic and biochemical analyses of the Pseudomonas aeruginosa Psl exopolysaccharide reveal overlapping roles for polysaccharide synthesis enzymes in Psl and LPS production. Mol. Microbiol. 73, 622-638. doi: 10.1111/j.1365-2958.2009.06795.x

Calix, J. J., Brady, A. M., Du, V. Y., Saad, J. S., and Nahm, M. H. (2014). Spectrum of pneumococcal serotype 11A variants results from incomplete loss of capsule O-acetylation. J. Clin. Microbiol. 52, 758-765. doi: 10.1128/JCM.02695-13

Calix, J. J., and Nahm, M. H. (2010). A new pneumococcal serotype, 11E, has a variably inactivated wcjE gene. J. Infect. Dis. 202, 29-38. doi: 10.1086/ 653123

Calix, J. J., Oliver, M. B., Sherwood, L. K., Beall, B. W., Hollingshead, S. K., and Nahm, M. H. (2011). Streptococcus pneumoniae serotype 9A isolates contain diverse mutations to wcjE that result in variable expression of serotype 9V-specific epitope. J. Infect. Dis. 204, 1585-1595. doi: 10.1093/infdis/ jir593

Calix, J. J., Saad, J. S., Brady, A. M., and Nahm, M. H. (2012). Structural characterization of Streptococcus pneumoniae serotype 9A capsule polysaccharide reveals role of glycosyl 6-O-acetyltransferase wcjE in serotype $9 \mathrm{~V}$ capsule biosynthesis and immunogenicity. J. Biol. Chem. 287, 13996-14003. doi: 10.1074/jbc.M112.346924

Campos, M., Martínez-Salazar, J. M., Lloret, L., Moreno, S., Núñez, C., Espín, G., et al. (1996). Characterization of the gene coding for GDP-mannose dehydrogenase (algD) from Azotobacter vinelandii. J. Bacteriol. 178, 1793-1799.

Cérantola, S., Lemassu-Jacquier, A., and Montrozier, H. (1999). Structural elucidation of a novel exopolysaccharide produced by a mucoid clinical isolate of Burkholderia cepacia. Characterization of a trisubstituted glucuronic acid residue in a heptasaccharide repeating unit. Eur. J. Biochem. 260, 373-383. doi: 10.1046/j.1432-1327.1999.00171.x

Cerca, N., Jefferson, K. K., Maira-Litràn, T., Pier, D. B., Kelly-Quintos, C., Goldmann, D. A., et al. (2007). Molecular basis for preferential protective efficacy of antibodies directed to the poorly acetylated form of staphylococcal poly-N-acetyl-beta-(1-6)-glucosamine. Infect. Immun. 75, 3406-3413. doi: 10.1128/IAI.00078-07

Cescutti, P., Bosco, M., Picotti, F., Impallomeni, G., Leitão, J. H., Richau, J. A., et al. (2000). Structural study of the exopolysaccharide produced by a clinical isolate of Burkholderia cepacia. Biochem. Biophys. Res. Commun. 273, 1088-1094. doi: 10.1006/bbrc.2000.3059

Cescutti, P., Foschiatti, M., Furlanis, L., Lagatolla, C., and Rizzo, R. (2010). Isolation and characterisation of the biological repeating unit of cepacian, the exopolysaccharide produced by bacteria of the Burkholderia cepacia complex. Carbohydr. Res. 345, 1455-1460. doi: 10.1016/j.carres.2010.03.029

Cescutti, P., Impallomeni, G., Garozzo, D., and Rizzo, R. (2011). O-Acetyl location on cepacian, the principal exopolysaccharide of Burkholderia cepacia complex bacteria. Carbohydr. Res. 346, 2905-2912. doi: 10.1016/j.carres.2011.10.011

Cescutti, P., Scussolin, S., Herasimenka, Y., Impallomeni, G., Bicego, M., and Rizzo, R. (2006). First report of a lyase for cepacian, the polysaccharide produced by Burkholderia cepacia complex bacteria. Biochem. Biophys. Res. Commun. 339, 821-826. doi: 10.1016/j.bbrc.2005.11.104

Chattoraj, S. S., Murthy, R., Ganesan, S., Goldberg, J. B., Zhao, Y., Hershenson, M. B., et al. (2010). Pseudomonas aeruginosa alginate promotes Burkholderia cenocepacia persistence in cystic fibrosis transmembrane conductance regulator knockout mice. Infect. Immun. 78, 984-993. doi: 10.1128/IAI.01192-09

Chitnis, C. E., and Ohman, D. E. (1990). Cloning of Pseudomonas aeruginosa algG, which controls alginate structure. J. Bacteriol. 172, 2894-2900.

Choi, A. H. K., Slamti, L., Avci, F. Y., Pier, G. B., and Maira-Litràn, T. (2009). The pgaABCD locus of Acinetobacter baumannii encodes the production of poly-beta-1-6-N-acetylglucosamine, which is critical for biofilm formation. J. Bacteriol. 191, 5953-5963. doi: 10.1128/JB.00647-09

Chotirmall, S. H., and McElvaney, N. G. (2014). Fungi in the cystic fibrosis lung: bystanders or pathogens? Int. J. Biochem. Cell Biol. 52, 161-173. doi: 10.1016/j.biocel.2014.03.001

Christensen, G. D., Barker, L. P., Mawhinney, T. P., Baddour, L. M., and Simpson, W. A. (1990). Identification of an antigenic marker of slime production for Staphylococcus epidermidis. Infect. Immun. 58, 2906-2911.
Cody, A. J., Field, D., Feil, E. J., Stringer, S., Deadman, M. E., Tsolaki, A. G., et al. (2003). High rates of recombination in otitis media isolates of non-typeable Haemophilus influenzae. Infect. Genet. Evol. 3, 57-66. doi: 10.1016/S15671348(02)00152-1

Colvin, K. M., Alnabelseya, N., Baker, P., Whitney, J. C., Howell, P. L., and Parsek, M. R. (2013). PelA deacetylase activity is required for Pel polysaccharide synthesis in Pseudomonas aeruginosa. J. Bacteriol. 195, 2329-2339. doi: 10.1128/JB.02150-12

Colwell, R. R., Huq, A., Islam, M. S., Aziz, K. M. A., Yunus, M., Khan, N. H., et al. (2003). Reduction of cholera in Bangladeshi villages by simple filtration. Proc. Natl. Acad. Sci. U.S.A. 100, 1051-1055. doi: 10.1073/pnas.0237386100

Cramton, S. E., Gerke, C., Schnell, N. F., Nichols, W. W., and Götz, F. (1999). The intercellular adhesion (ica) locus is present in Staphylococcus aureus and is required for biofilm formation. Infect. Immun. 67, 5427-5433.

Cress, B. F., Englaender, J. A., He, W., Kasper, D., Linhardt, R. J., and Koffas, M. A. G. (2014). Masquerading microbial pathogens: capsular polysaccharides mimic host-tissue molecules. FEMS Microbiol. Rev. 38, 660-697. doi: 10.1111/1574-6976.12056

Cuzzi, B., Cescutti, P., Furlanis, L., Lagatolla, C., Sturiale, L., Garozzo, D., et al. (2012). Investigation of bacterial resistance to the immune system response: cepacian depolymerisation by reactive oxygen species. Innate Immun. 18, 661-671. doi: 10.1177/1753425911435954

Cywes-Bentley, C., Skurnik, D., Zaidi, T., Roux, D., Deoliveira, R. B., Garrett, W. S., et al. (2013). Antibody to a conserved antigenic target is protective against diverse prokaryotic and eukaryotic pathogens. Proc. Natl. Acad. Sci. U.S.A. 110, E2209-E2218. doi: 10.1073/pnas.1303573110

Damron, F. H., Davis, M. R., Withers, T. R., Ernst, R. K., Goldberg, J. B., Yu, G., et al. (2011). Vanadate and triclosan synergistically induce alginate production by Pseudomonas aeruginosa strain PAO1. Mol. Microbiol. 81, 554-570. doi: 10.1111/j.1365-2958.2011.07715.x

Day, D. F. (1988). Bacterial alginate control of enzyme modification. Ann. N. Y. Acad. Sci. 542, 107-110. doi: 10.1111/j.1749-6632.1988.tb25813.x

DeAngelis, P. L. (2002). Evolution of glycosaminoglycans and their glycosyltransferases: implications for the extracellular matrices of animals and the capsules of pathogenic bacteria. Anat. Rec. 268, 317-326. doi: 10.1002/ar.10163

DeAngelis, P. L., Gunay, N. S., Toida, T., Mao, W.-J., and Linhardt, R. J. (2002). Identification of the capsular polysaccharides of Type D and F Pasteurella multocida as unmodified heparin and chondroitin, respectively. Carbohydr. Res. 337, 1547-1552. doi: 10.1016/S0008-6215(02)00219-7

Doig, P., Smith, N. R., Todd, T., and Irvin, R. T. (1987). Characterization of the binding of Pseudomonas aeruginosa alginate to human epithelial cells. Infect. Immun. 55, 1517-1522.

Donati, I., Holtan, S., Mørch, Y. A., Borgogna, M., Dentini, M., and Skjak-Braek, G. (2005). New hypothesis on the role of alternating sequences in calcium-alginate gels. Biomacromolecules 6, 1031-1040. doi: 10.1021/bm049306e

Elias, S., and Banin, E. (2012). Multi-species biofilms: living with friendly neighbors. FEMS Microbiol. Rev. 36, 990-1004. doi: 10.1111/j.1574-6976. 2012.00325.x

Ellerbroek, P. M., Lefeber, D. J., van Veghel, R., Scharringa, J., Brouwer, E., Gerwig, G. J., et al. (2004). O-acetylation of cryptococcal capsular glucuronoxylomannan is essential for interference with neutrophil migration. J. Immunol. 173, 7513-7520. doi: 10.4049/jimmunol.173. 12.7513

Ertesvåg, H., Doseth, B., Larsen, B., Skjåk-Braek, G., and Valla, S. (1994). Cloning and expression of an Azotobacter vinelandii mannuronan C-5-epimerase gene. J. Bacteriol. 176, 2846-2853.

Ertesvåg, H., Høidal, H. K., Hals, I. K., Rian, A., Doseth, B., and Valla, S. (1995). A family of modular type mannuronan C-5-epimerase genes controls alginate structure in Azotobacter vinelandii. Mol. Microbiol. 16, 719-731. doi: 10.1111/j.1365-2958.1995.tb02433.x

Ertesvåg, H., Høidal, H. K., Skjåk-Braek, G., and Valla, S. (1998). The Azotobacter vinelandii mannuronan C-5-epimerase AlgE1 consists of two separate catalytic domains. J. Biol. Chem. 273, 30927-30932. doi: 10.1074/jbc.273.47. 30927

Ertesvåg, H., and Valla, S. (1999). The A modules of the Azotobacter vinelandii mannuronan-C-5-epimerase AlgE1 are sufficient for both epimerization and binding of $\mathrm{Ca}^{2+}$. J. Bacteriol. 181, 3033-3038. 
Esko, J. D., and Lindahl, U. (2001). Molecular diversity of heparan sulfate. J. Clin. Invest. 108, 169-173. doi: 10.1172/JCI13530

Evans, L. R., and Linker, A. (1973). Production and characterization of the slime polysaccharide of Pseudomonas aeruginosa. J. Bacteriol. 116, 915-924.

Farrell, E. K., and Tipton, P. A. (2012). Functional characterization of AlgL, an alginate lyase from Pseudomonas aeruginosa. Biochemistry 51, 10259-10266. doi: $10.1021 / \mathrm{bi301425r}$

Faruque, S. M., Albert, M. J., and Mekalanos, J. J. (1998). Epidemiology, genetics, and ecology of toxigenic Vibrio cholerae. Microbiol. Mol. Biol. Rev. 62, 13011314.

Faruque, S. M., Biswas, K., Udden, S. M. N., Ahmad, Q. S., Sack, D. A., Nair, G. B., et al. (2006). Transmissibility of cholera: in vivo-formed biofilms and their relationship to infectivity and persistence in the environment. Proc. Natl. Acad. Sci. U.S.A. 103, 6350-6355. doi: 10.1073/pnas. 0601277103

Ferreira, A. S., Leitão, J. H., Silva, I. N., Pinheiro, P. F., Sousa, S. A., Ramos, C. G., et al. (2010). Distribution of cepacian biosynthesis genes among environmental and clinical Burkholderia strains and role of cepacian exopolysaccharide in resistance to stress conditions. Appl. Environ. Microbiol. 76, 441-450. doi: 10.1128/AEM.01828-09

Ferreira, A. S., Silva, I. N., Oliveira, V. H., Cunha, R., and Moreira, L. M. (2011). Insights into the role of extracellular polysaccharides in Burkholderia adaptation to different environments. Front. Cell Infect. Microbiol. 1:16. doi: $10.3389 /$ fcimb. 2011.00016

Fischer, F. G., and Dorfel, H. (1955). Die polyuronsäuren der braunalgen (Kohlenhydrate der Algen I). Biol. Chem. 302, 186-203. doi: 10.1515/bchm2.1955.302.1-2.186

Flemming, H.-C., and Wingender, J. (2010). The biofilm matrix. Nat. Rev. Microbiol. 8, 623-633. doi: 10.1038/nrmicro2415

Fong, J. C. N., Syed, K. A., Klose, K. E., and Yildiz, F. H. (2010). Role of Vibrio polysaccharide (vps) genes in VPS production, biofilm formation and Vibrio cholerae pathogenesis. Microbiology 156, 2757-2769. doi: 10.1099/mic.0.040196-0

Forman, S., Bobrov, A. G., Kirillina, O., Craig, S. K., Abney, J., Fetherston, J. D., et al. (2006). Identification of critical amino acid residues in the plague biofilm Hms proteins. Microbiology 152, 3399-3410. doi: 10.1099/mic.0.29224-0

Fox, K. L., Yildirim, H. H., Deadman, M. E., Schweda, E. K. H., Moxon, E. R., and Hood, D. W. (2005). Novel lipopolysaccharide biosynthetic genes containing tetranucleotide repeats in Haemophilus influenzae, identification of a gene for adding O-acetyl groups. Mol. Microbiol. 58, 207-216. doi: 10.1111/j.13652958.2005.04814.x

Franklin, M. J., Chitnis, C. E., Gacesa, P., Sonesson, A., White, D. C., and Ohman, D. E. (1994). Pseudomonas aeruginosa $\mathrm{AlgG}$ is a polymer level alginate C5-mannuronan epimerase. J. Bacteriol. 176, 1821-1830.

Franklin, M. J., Douthit, S. A., and McClure, M. A. (2004). Evidence that the algI/algJ gene cassette, required for $\mathrm{O}$ acetylation of Pseudomonas aeruginosa alginate, evolved by lateral gene transfer. J. Bacteriol. 186, 4759-4773. doi: 10.1128/JB.186.14.4759-4773.2004

Franklin, M. J., Nivens, D. E., Weadge, J. T., and Howell, P. L. (2011). Biosynthesis of the Pseudomonas aeruginosa Extracellular Polysaccharides, Alginate, Pel, and Psl. Front. Microbiol. 2:167. doi: 10.3389/fmicb.2011. 00167

Franklin, M. J., and Ohman, D. E. (1993). Identification of algF in the alginate biosynthetic gene cluster of Pseudomonas aeruginosa which is required for alginate acetylation. J. Bacteriol. 175, 5057-5065.

Franklin, M. J., and Ohman, D. E. (1996). Identification of algI and algJ in the Pseudomonas aeruginosa alginate biosynthetic gene cluster which are required for alginate $\mathrm{O}$ acetylation. J. Bacteriol. 178, 2186-2195.

Franklin, M. J., and Ohman, D. E. (2002). Mutant analysis and cellular localization of the AlgI, AlgJ, and AlgF proteins required for O acetylation of alginate in Pseudomonas aeruginosa. J. Bacteriol. 184, 3000-3007. doi: 10.1128/JB.184.11.3000-3007.2002

Frasa, H., Procee, J., Torensma, R., Verbruggen, A., Algra, A., RozenbergArska, M., et al. (1993). Escherichia coli in bacteremia: O-acetylated K1 strains appear to be more virulent than non-O-acetylated K1 strains. J. Clin. Microbiol. 31, 3174-3178.

Friedman, L., and Kolter, R. (2004). Genes involved in matrix formation in Pseudomonas aeruginosa PA14 biofilms. Mol. Microbiol. 51, 675-690. doi: 10.1046/j.1365-2958.2003.03877.x
Fujihara, H., Kagaya, K., and Fukazawa, Y. (1997). Anti-chemotactic activity of capsular polysaccharide of Cryptococcus neoformans in vitro. Microbiol. Immunol. 41, 657-664. doi: 10.1111/j.1348-0421.1997.tb01908.x

Fusco, P. C., Farley, E. K., Huang, C.-H., Moore, S., and Michon, F. (2007). Protective meningococcal capsular polysaccharide epitopes and the role of $\mathrm{O}$ acetylation. Clin. Vaccine Immunol. 14, 577-584. doi: 10.1128/CVI.00009-07

Gacesa, P. (1988). Alginates. Carbohydr. Polym. 8, 161-182. doi: 10.1016/01448617(88)90001-X

Gening, M. L., Maira-Litràn, T., Kropec, A., Skurnik, D., Grout, M., Tsvetkov, Y. E., et al. (2010). Synthetic \{beta\}-(1->6)-linked $\mathrm{N}$-acetylated and nonacetylated oligoglucosamines used to produce conjugate vaccines for bacterial pathogens. Infect. Immun. 78, 764-772. doi: 10.1128/IAI.01093-09

Gerke, C., Kraft, A., Süssmuth, R., Schweitzer, O., and Götz, F. (1998). Characterization of the $\mathrm{N}$-acetylglucosaminyltransferase activity involved in the biosynthesis of the Staphylococcus epidermidis polysaccharide intercellular adhesin. J. Biol. Chem. 273, 18586-18593. doi: 10.1074/jbc.273.29.18586

Gimmestad, M., Sletta, H., Ertesvåg, H., Bakkevig, K., Jain, S., Suh, S. J., et al. (2003). The Pseudomonas fluorescens AlgG protein, but not its mannuronan C5 -epimerase activity, is needed for alginate polymer formation. J. Bacteriol. 185, 3515-3523. doi: 10.1128/JB.185.12.3515-3523.2003

Gimmestad, M., Steigedal, M., Ertesvåg, H., Moreno, S., Christensen, B. E., Espìn, G., et al. (2006). Identification and characterization of an Azotobacter vinelandii type I secretion system responsible for export of the AlgEtype mannuronan C-5-epimerases. J. Bacteriol. 188, 5551-5560. doi: 10.1128/JB.00236-06

González, J. E., Semino, C. E., Wang, L. X., Castellano-Torres, L. E., and Walker, G. C. (1998). Biosynthetic control of molecular weight in the polymerization of the octasaccharide subunits of succinoglycan, a symbiotically important exopolysaccharide of Rhizobium meliloti. Proc. Natl. Acad. Sci. U.S.A. 95, 13477-13482. doi: 10.1073/pnas.95.23.13477

Gorin, P., and Spencer, J. (1966). Exocellular alginic acid from Azotobacter vinelandii. Can. J. Chem. 44, 993-998. doi: 10.1139/v66-147

Govan, J. R., and Deretic, V. (1996). Microbial pathogenesis in cystic fibrosis: mucoid Pseudomonas aeruginosa and Burkholderia cepacia. Microbiol. Rev. 60, 539-574.

Govan, J. R., Fyfe, J. A., and Jarman, T. R. (1981). Isolation of alginate-producing mutants of Pseudomonas fluorescens, Pseudomonas putida and Pseudomonas mendocina. J. Gen. Microbiol. 125, 217-220. doi: 10.1099/00221287-125-1-217

Grant, G. T., Morris, E. R., Rees, D. A., Smith, P., and Thom, D. (1973). Biological interactions between polysaccharides and divalent cations: the egg-box model. FEBS Lett. 32, 195-198. doi: 10.1016/0014-5793(73)80770-7

Halpern, M., Broza, Y. B., Mittler, S., Arakawa, E., and Broza, M. (2004). Chironomid egg masses as a natural reservoir of Vibrio cholerae nonO1 and non-O139 in freshwater habitats. Microb. Ecol. 47, 341-349. doi: 10.1007/s00248-003-2007-6

Haug, A., Larsen, B., and Smidsrød, O. (1966). A study of the constitution of alginic acid by partial acid hydrolysis. Acta Chem. Scand. 20, 183-190. doi: 10.3891/acta.chem.scand.20-0183

Haug, A., Larsen, B., and Smidsrød, O. (1967). Alkaline degradation of alginate. Acta Chem. Scand. 21, 2859-2870. doi: 10.3891/acta.chem.scand.21-2859

Hay, I. D., Wang, Y., Moradali, M., Rehman, Z. U., and Rehm, B. H. A. (2014). Genetics and regulation of bacterial alginate production. Environ. Microbiol. 16, 2997-3011. doi: 10.1111/1462-2920.12389

Heilmann, C., Gerke, C., Perdreau-Remington, F., and Götz, F. (1996a). Characterization of Tn917 insertion mutants of Staphylococcus epidermidis affected in biofilm formation. Infect. Immun. 64, 277-282.

Heilmann, C., Schweitzer, O., Gerke, C., Vanittanakom, N., Mack, D., and Götz, F. (1996b). Molecular basis of intercellular adhesion in the biofilm-forming Staphylococcus epidermidis. Mol. Microbiol. 20, 1083-1091. doi: 10.1111/j.13652958.1996.tb02548.x

Hisamatsu, M., Nomura, S., Shutsrirung, A., Obata, H., Teranishi, K., Yamada, T., et al. (1997). Structural characterization of a new acidic exopolysaccharide and cyclic $(1 \rightarrow 2) \beta$-glucan produced by Rhizobium huakuii forming nodules on Astragalus sinicus. J. Ferment. Bioeng. 83, 315-320. doi: 10.1016/S0922338X(97)80135-3

Høidal, H. K., Glaerum Svanem, B. I., Gimmestad, M., and Valla, S. (2000). Mannuronan C-5 epimerases and cellular differentiation of Azotobacter vinelandii. Environ. Microbiol. 2, 27-38. doi: 10.1046/j.1462-2920.2000.00074.x 
Horsman, S. R., Moore, R. A., and Lewenza, S. (2012). Calcium chelation by alginate activates the type III secretion system in mucoid Pseudomonas aeruginosa biofilms. PLoS ONE 7:e46826. doi: 10.1371/journal.pone.0046826

Hostetter, M. K., Thomas, M. L., Rosen, F. S., and Tack, B. F. (1982). Binding of C3b proceeds by a transesterification reaction at the thiolester site. Nature 298, 72-75. doi: 10.1038/298072b0

Huq, A., Colwell, R. R., Chowdhury, M. A., Xu, B., Moniruzzaman, S. M., Islam, M. S., et al. (1995). Coexistence of Vibrio cholerae O1 and O139 Bengal in plankton in Bangladesh. Lancet 345, 1249. doi: 10.1016/S0140-6736(95)92038-2

Huq, A., Small, E. B., West, P. A., Huq, M. I., Rahman, R., and Colwell, R. R. (1983). Ecological relationships between Vibrio cholerae and planktonic crustacean copepods. Appl. Environ. Microbiol. 45, 275-283.

Huq, A., Xu, B., Chowdhury, M. A., Islam, M. S., Montilla, R., and Colwell, R. R. (1996). A simple filtration method to remove plankton-associated Vibrio cholerae in raw water supplies in developing countries. Appl. Environ. Microbiol. 62, 2508-2512.

Itoh, Y., Rice, J. D., Goller, C., Pannuri, A., Taylor, J., Meisner, J., et al. (2008). Roles of pgaABCD genes in synthesis, modification, and export of the Escherichia coli biofilm adhesin poly-beta-1,6-N-acetyl-D-glucosamine. J. Bacteriol. 190, 3670-3680. doi: 10.1128/JB.01920-07

Izano, E. A., Sadovskaya, I., Vinogradov, E., Mulks, M. H., Velliyagounder, K., Ragunath, C., et al. (2007). Poly-N-acetylglucosamine mediates biofilm formation and antibiotic resistance in Actinobacillus pleuropneumoniae. Microb. Pathog. 43, 1-9. doi: 10.1016/j.micpath.2007.02.004

Izano, E. A., Sadovskaya, I., Wang, H., Vinogradov, E., Ragunath, C., Ramasubbu, N., et al. (2008). Poly-N-acetylglucosamine mediates biofilm formation and detergent resistance in Aggregatibacter actinomycetemcomitans. Microb. Pathog. 44, 52-60. doi: 10.1016/j.micpath.2007.08.004

Jain, S., Franklin, M. J., Ertesvåg, H., Valla, S., and Ohman, D. E. (2003). The dual roles of AlgG in C-5-epimerization and secretion of alginate polymers in Pseudomonas aeruginosa. Mol. Microbiol. 47, 1123-1133. doi: 10.1046/j.13652958.2003.03361.x

Jansson, P. E., Lindberg, B., Lindquist, U., and Ljungberg, J. (1987). Structural studies of the capsular polysaccharide from Streptococcus pneumoniae types $15 \mathrm{~B}$ and 15C. Carbohydr. Res. 162, 111-116. doi: 10.1016/0008-6215(87)80205-7

Jarrett, C. O., Deak, E., Isherwood, K. E., Oyston, P. C., Fischer, E. R., Whitney, A. R., et al. (2004). Transmission of Yersinia pestis from an infectious biofilm in the flea vector. J. Infect. Dis. 190, 783-792. doi: 10.1086/422695

Joyce, J. G., Abeygunawardana, C., Xu, Q., Cook, J. C., Hepler, R., Przysiecki, C. T., et al. (2003). Isolation, structural characterization, and immunological evaluation of a high-molecular-weight exopolysaccharide from Staphylococcus aureus. Carbohydr. Res. 338, 903-922. doi: 10.1016/S0008-6215(03)00045-4

Kaper, J. B., Morris, J. G., and Levine, M. M. (1995). Cholera. Clin. Microbiol. Rev. $8,48-86$.

Kelley, L. A., and Sternberg, M. J. E. (2009). Protein structure prediction on the Web: a case study using the Phyre server. Nat. Protoc. 4, 363-371. doi: 10.1038 /nprot.2009.2

Kim, M. L., and Slauch, J. M. (1999). Effect of acetylation (O-factor 5) on the polyclonal antibody response to Salmonella typhimurium O-antigen. FEMS Immunol. Med. Microbiol. 26, 83-92. doi: 10.1111/j.1574-695X.1999.tb01375.x

Kim, W., Tengra, F. K., Young, Z., Shong, J., Marchand, N., Chan, H. K., et al. (2013). Spaceflight promotes biofilm formation by Pseudomonas aeruginosa. PLoS ONE 8:e62437. doi: 10.1371/journal.pone.0062437

Kjellén, L., and Lindahl, U. (1991). Proteoglycans: structures and interactions. Annu. Rev. Biochem. 60, 443-475. doi: 10.1146/annurev.bi.60.070191.002303

Kline, K. A., Schwartz, D. J., Gilbert, N. M., Hultgren, S. J., and Lewis, A. L. (2012). Immune modulation by group B Streptococcus influences host susceptibility to urinary tract infection by uropathogenic Escherichia coli. Infect. Immun. 80, 4186-4194. doi: 10.1128/IAI.00684-12

Kline, K. A., Schwartz, D. J., Lewis, W. G., Hultgren, S. J., and Lewis, A. L. (2011). Immune activation and suppression by group B streptococcus in a murine model of urinary tract infection. Infect. Immun. 79, 3588-3595. doi: 10.1128/IAI.00122-11

Korotkov, K. V., Sandkvist, M., and Hol, W. G. J. (2012). The type II secretion system: biogenesis, molecular architecture and mechanism. Nat. Rev. Microbiol. 10, 336-351. doi: 10.1038/nrmicro2762

Kozel, T. R., Levitz, S. M., Dromer, F., Gates, M. A., Thorkildson, P., and Janbon, G. (2003). Antigenic and biological characteristics of mutant strains of
Cryptococcus neoformans lacking capsular O acetylation or xylosyl side chains. Infect. Immun. 71, 2868-2875. doi: 10.1128/IAI.71.5.2868-2875.2003

Krieg, D. P., Bass, J. A., and Mattingly, S. J. (1986). Aeration selects for mucoid phenotype of Pseudomonas aeruginosa. J. Clin. Microbiol. 24, 986-990.

Kuo, M.-S., Mort, A. J., and Dell, A. (1986). Identification and location of l-glycerate, an unusual acyl substituent in gellan gum. Carbohydr. Res. 156, 173-187. doi: 10.1016/S0008-6215(00)90109-5

Kwon, K. K., Lee, H. S., Jung, S., Yim, J., Lee, J., and Lee, H. K. (2002). Isolation and identification of biofilm-forming marine bacteria on glass surfaces in dae-ho dike, Korea. J. Microbiol. 40, 260-266.

Laurent, T. C., and Fraser, J. R. (1992). Hyaluronan. FASEB J. 6, 2397-2404.

Learn, D. B., Brestel, E. P., and Seetharama, S. (1987). Hypochlorite scavenging by Pseudomonas aeruginosa alginate. Infect. Immun. 55, 1813-1818.

Lee, J. W., and Day, F. (1998). The separation of alginate biosynthesis and acetylation in Pseudomonas syringae. Can. J. Microbiol. 44, 394-398. doi: 10.1139/w98-008

Lenhart, T. R., Duncan, K. E., Beech, I. B., Sunner, J. A., Smith, W., Bonifay, V., et al. (2014). Identification and characterization of microbial biofilm communities associated with corroded oil pipeline surfaces. Biofouling 30, 823-835. doi: 10.1080/08927014.2014.931379

Leuck, A.-M., Johnson, J. R., and Dunny, G. M. (2014). A widely used in vitro biofilm assay has questionable clinical significance for enterococcal endocarditis. PLoS ONE 9:e107282. doi: 10.1371/journal.pone.0107282

Lewis, A. L., Cao, H., Patel, S. K., Diaz, S., Ryan, W., Carlin, A. F., et al. (2007). NeuA sialic acid O-acetylesterase activity modulates $\mathrm{O}$-acetylation of capsular polysaccharide in group B Streptococcus. J. Biol. Chem. 282, 27562-27571. doi: 10.1074/jbc.M700340200

Lewis, A. L., Hensler, M. E., Varki, A., and Nizet, V. (2006). The group B streptococcal sialic acid O-acetyltransferase is encoded by neuD, a conserved component of bacterial sialic acid biosynthetic gene clusters. J. Biol. Chem. 281, 11186-11192. doi: 10.1074/jbc.M513772200

Li, J.-P., Gong, F., Hagner-McWhirter, A., Forsberg, E., Abrink, M., Kisilevsky, R., et al. (2003). Targeted disruption of a murine glucuronyl C5-epimerase gene results in heparan sulfate lacking L-iduronic acid and in neonatal lethality. J. Biol. Chem. 278, 28363-28366. doi: 10.1074/jbc.C300219200

Limoli, D. H., Rockel, A. B., Host, K. M., Jha, A., Kopp, B. T., Hollis, T. et al. (2014). Cationic antimicrobial peptides promote microbial mutagenesis and pathoadaptation in chronic infections. PLoS Pathog. 10:e1004083. doi: 10.1371/journal.ppat.1004083

Lin, L. P., and Sadoff, H. L. (1969). Chemical composition of Azotobacter vinelandii cysts. J. Bacteriol. 100, 480-486.

Linker, A., Evans, L. R., and Impallomeni, G. (2001). The structure of a polysaccharide from infectious strains of Burkholderia cepacia. Carbohydr. Res. 335, 45-54. doi: 10.1016/S0008-6215(01)00205-1

Linker, A., and Jones, R. S. (1966). A new polysaccharide resembling alginic acid isolated from pseudomonads. J. Biol. Chem. 241, 3845-3851.

Little, D. J., Bamford, N. C., Podrovskaya, V., Robinson, H., Nitz, M., and Howell, P. L. (2014a). Structural basis for the de-N-acetylation of poly- $\beta-1,6-\mathrm{N}$-acetylD-glucosamine in Gram-positive bacteria. J. Biol. Chem. 289, 35907-35917. doi: 10.1074/jbc.M114.611400

Little, D. J., Li, G., Ing, C., DiFrancesco, B. R., Bamford, N. C., Robinson, H., et al. (2014b). Modification and periplasmic translocation of the biofilm exopolysaccharide poly- $\beta-1,6-\mathrm{N}$-acetyl-d-glucosamine. Proc. Natl. Acad. Sci. U.S.A. 111, 11013-11018. doi: 10.1073/pnas.1406388111

Little, D. J., Poloczek, J., Whitney, J. C., Robinson, H., Nitz, M., and Howell, P. L. (2012). The structure- and metal-dependent activity of Escherichia coli $\mathrm{PgaB}$ provides insight into the partial de-N-acetylation of poly- $\beta-1,6-\mathrm{N}$ acetyl-D-glucosamine. J. Biol. Chem. 287, 31126-31137. doi: 10.1074/jbc.M112. 390005

Lyczak, J. B., Cannon, C. L., and Pier, G. B. (2000). Establishment of Pseudomonas aeruginosa infection: lessons from a versatile opportunist. Microbes Infect. 2, 1051-1060. doi: 10.1016/S1286-4579(00)01259-4

Ma, L., Wang, J., Wang, S., Anderson, E. M., Lam, J. S., Parsek, M. R. et al. (2012). Synthesis of multiple Pseudomonas aeruginosa biofilm matrix exopolysaccharides is post-transcriptionally regulated. Environ. Microbiol. 14, 1995-2005. doi: 10.1111/j.1462-2920.2012.02753.x

Maalej, H., Boisset, C., Hmidet, N., Buon, L., Heyraud, A., and Nasri, M. (2014). Purification and structural data of a highly substituted exopolysaccharide 
from Pseudomonas stutzeri AS22. Carbohydr. Polym. 112, 404-411. doi: 10.1016/j.carbpol.2014.06.003

Mack, D., Fischer, W., Krokotsch, A., Leopold, K., Hartmann, R., Egge, H., et al. (1996). The intercellular adhesin involved in biofilm accumulation of Staphylococcus epidermidis is a linear beta-1,6-linked glucosaminoglycan: purification and structural analysis. J. Bacteriol. 178, 175-183.

Mahenthiralingam, E., Baldwin, A., and Vandamme, P. (2002). Burkholderia cepacia complex infection in patients with cystic fibrosis. J. Med. Microbiol. 51, 533-538.

Mahenthiralingam, E., Urban, T. A., and Goldberg, J. B. (2005). The multifarious, multireplicon Burkholderia cepacia complex. Nat. Rev. Microbiol. 3, 144-156. doi: 10.1038/nrmicro1085

Mai, G. T., Seow, W. K., Pier, G. B., McCormack, J. G., and Thong, Y. H. (1993). Suppression of lymphocyte and neutrophil functions by Pseudomonas aeruginosa mucoid exopolysaccharide (alginate): reversal by physicochemical, alginase, and specific monoclonal antibody treatments. Infect. Immun. 61, 559-564.

Maira-Litràn, T., Kropec, A., Abeygunawardana, C., Joyce, J., Mark, G., Goldmann, D. A., et al. (2002). Immunochemical properties of the staphylococcal poly-Nacetylglucosamine surface polysaccharide. Infect. Immun. 70, 4433-4440.

Maira-Litràn, T., Kropec, A., Goldmann, D., and Pier, G. B. (2004). Biologic properties and vaccine potential of the staphylococcal poly$\mathrm{N}$-acetyl glucosamine surface polysaccharide. Vaccine 22, 872-879. doi: 10.1016/j.vaccine.2003.11.033.

Marcus, H., and Baker, N. R. (1985). Quantitation of adherence of mucoid and nonmucoid Pseudomonas aeruginosa to hamster tracheal epithelium. Infect. Immun. 47, 723-729.

Marty, N., Dournes, J. L., Chabanon, G., and Montrozier, H. (1992). Influence of nutrient media on the chemical composition of the exopolysaccharide from mucoid and non-mucoid Pseudomonas aeruginosa. FEMS Microbiol. Lett. 77, 35-44. doi: 10.1111/j.1574-6968.1992.tb05486.x

Marzocca, M. P., Harding, N. E., Petroni, E. A., Cleary, J. M., and Ielpi, L. (1991) Location and cloning of the ketal pyruvate transferase gene of Xanthomonas campestris. J. Bacteriol. 173, 7519-7524.

Matz, C., McDougald, D., Moreno, A. M., Yung, P. Y., Yildiz, F. H., and Kjelleberg, S. (2005). Biofilm formation and phenotypic variation enhance predation-driven persistence of Vibrio cholerae. Proc. Natl. Acad. Sci. U.S.A. 102, 16819-16824. doi: 10.1073/pnas.0505350102

McKenney, D., Hübner, J., Muller, E., Wang, Y., Goldmann, D. A., and Pier, G. B. (1998). The ica locus of Staphylococcus epidermidis encodes production of the capsular polysaccharide/adhesin. Infect. Immun. 66, 4711-4720.

McKenney, D., Pouliot, K. L., Wang, Y., Murthy, V., Ulrich, M., Döring, G., et al. (1999). Broadly protective vaccine for Staphylococcus aureus based on an in vivo-expressed antigen. Science 284, 1523-1527. doi: $10.1126 /$ science.284.5419.1523

McNeely, T. B., Staub, J. M., Rusk, C. M., Blum, M. J., and Donnelly, J. J. (1998). Antibody responses to capsular polysaccharide backbone and $\mathrm{O}$-acetate side groups of Streptococcus pneumoniae type $9 \mathrm{~V}$ in humans and rhesus macaques. Infect. Immun. 66, 3705-3710.

Melin, M., Trzciñski, K., Antonio, M., Meri, S., Adegbola, R., Kaijalainen, T., et al. (2010). Serotype-related variation in susceptibility to complement deposition and opsonophagocytosis among clinical isolates of Streptococcus pneumoniae. Infect. Immun. 78, 5252-5261. doi: 10.1128/IAI.00739-10

Michon, F., Huang, C. H., Farley, E. K., Hronowski, L., Di, J., and Fusco, P. C. (2000). Structure activity studies on group C meningococcal polysaccharideprotein conjugate vaccines: effect of $\mathrm{O}$-acetylation on the nature of the protective epitope. Dev. Biol. (Basel) 103, 151-160.

Monday, S. R., and Schiller, N. L. (1996). Alginate synthesis in Pseudomonas aeruginosa: the role of AlgL (alginate lyase) and AlgX. J. Bacteriol. 178, 625-632.

Morea, A., Mathee, K., Franklin, M. J., Giacomini, A., O’Regan, M., and Ohman, D. E. (2001). Characterization of algG encoding C5-epimerase in the alginate biosynthetic gene cluster of Pseudomonas fluorescens. Gene 278, 107-114. doi: 10.1016/S0378-1119(01)00685-0

Moynihan, P. J., and Clarke, A. J. (2011). O-Acetylated peptidoglycan: controlling the activity of bacterial autolysins and lytic enzymes of innate immune systems. Int. J. Biochem. Cell Biol. 43, 1655-1659. doi: 10.1016/j.biocel.2011.08.007

Nivens, D. E., Ohman, D. E., Williams, J., and Franklin, M. J. (2001). Role of alginate and its $\mathrm{O}$ acetylation in formation of Pseudomonas aeruginosa microcolonies and biofilms. J. Bacteriol. 183, 1047-1057. doi: 10.1128/JB.183.3.1047-1057.2001

Ohman, D. E. (1986). Molecular genetics of exopolysaccharide production by mucoid Pseudomonas aeruginosa. Eur. J. Clin. Microbiol. 5, 6-10. doi: 10.1007/BF02013452

Paletta, J. L., and Ohman, D. E. (2012). Evidence for two promoters internal to the alginate biosynthesis operon in Pseudomonas aeruginosa. Curr. Microbiol. 65, 770-775. doi: 10.1007/s00284-012-0228-y

Parise, G., Mishra, M., Itoh, Y., Romeo, T., and Deora, R. (2007). Role of a putative polysaccharide locus in Bordetella biofilm development. J. Bacteriol. 189, 750-760. doi: 10.1128/JB.00953-06

Peña, C., Hernández, L., and Galindo, E. (2006). Manipulation of the acetylation degree of Azotobacter vinelandii alginate by supplementing the culture medium with 3-(N-morpholino)-propane-sulfonic acid. Lett. Appl. Microbiol. 43, 200204. doi: 10.1111/j.1472-765X.2006.01925.x

Pier, G. B., Coleman, F., Grout, M., Franklin, M., and Ohman, D. E. (2001). Role of alginate $\mathrm{O}$ acetylation in resistance of mucoid Pseudomonas aeruginosa to opsonic phagocytosis. Infect. Immun. 69, 1895-1901. doi: 10.1128/IAI.69.3.1895-1901.2001

Pinto, V., and Berti, F. (2014). Exploring the Group B Streptococcus capsular polysaccharides: the structural diversity provides the basis for development of NMR-based identity assays. J. Pharm. Biomed. Anal. 98, 9-15. doi: 10.1016/j.jpba.2014.05.004

Pokrovskaya, V., Poloczek, J., Little, D. J., Griffiths, H., Howell, P. L., and Nitz, M. (2013). Functional Characterization of Staphylococcus epidermidis IcaB, a De$\mathrm{N}$-acetylase important for biofilm formation. Biochemistry 52, 5463-5471. doi: $10.1021 / \mathrm{bi} 400836 \mathrm{~g}$

Raedts, J., Kengen, S. W. M., and van der Oost, J. (2011). Occurrence of L-iduronic acid and putative D-glucuronyl C5-epimerases in prokaryotes. Glycoconj. J. 28, 57-66. doi: 10.1007/s10719-011-9324-7

Raedts, J., Lundgren, M., Kengen, S. W. M., Li, J.-P., and van der Oost, J. (2013). A novel bacterial enzyme with D-glucuronyl C5-epimerase activity. J. Biol. Chem. 288, 24332-24339. doi: 10.1074/jbc.M113.476440

Rajam, G., Carlone, G. M., and Romero-Steiner, S. (2007). Functional antibodies to the O-acetylated pneumococcal serotype 15B capsular polysaccharide have low cross-reactivities with serotype 15C. Clin. Vaccine Immunol. 14, 1223-1227. doi: 10.1128/CVI.00184-07

Ramphal, R., Guay, C., and Pier, G. B. (1987). Pseudomonas aeruginosa adhesins for tracheobronchial mucin. Infect. Immun. 55, 600-603.

Rehm, B. H., Ertesvåg, H., and Valla, S. (1996). A new Azotobacter vinelandii mannuronan C-5-epimerase gene (algG) is part of an alg gene cluster physically organized in a manner similar to that in Pseudomonas aeruginosa. J. Bacteriol. $178,5884-5889$.

Reuber, T. L., and Walker, G. C. (1993). Biosynthesis of succinoglycan, a symbiotically important exopolysaccharide of Rhizobium meliloti. Cell 74, 269280. doi: 10.1016/0092-8674(93)90418-P

Ridout, M. J., Brownsey, G. J., York, G. M., Walker, G. C., and Morris, V. J. (1997). Effect of o-acyl substituents on the functional behaviour of Rhizobium meliloti succinoglycan. Int. J. Biol. Macromol. 20, 1-7. doi: 10.1016/S01418130(96)01140-3

Riley, L. M., Weadge, J. T., Baker, P., Robinson, H., Codée, J. D. C., Tipton, P. A., et al. (2013). Structural and functional characterization of Pseudomonas aeruginosa AlgX: role of $\mathrm{AlgX}$ in alginate acetylation. J. Biol. Chem. 288, 22299-22314. doi: 10.1074/jbc.M113.484931

Robles-Price, A., Wong, T. Y., Sletta, H., Valla, S., and Schiller, N. L. (2004). $\mathrm{AlgX}$ is a periplasmic protein required for alginate biosynthesis in Pseudomonas aeruginosa. J. Bacteriol. 186, 7369-7377. doi: 10.1128/JB.186.21.7369-7377.2004

Rodriguez, M. L., Jann, B., and Jann, K. (1988). Structure and serological characteristics of the capsular K4 antigen of Escherichia coli O5:K4:H4, a fructose-containing polysaccharide with a chondroitin backbone. Eur. J. Biochem. 177, 117-124. doi: 10.1111/j.1432-1033.1988.tb14351.x

Rozeboom, H. J., Bjerkan, T. M., Kalk, K. H., Ertesvåg, H., Holtan, S., Aachmann, F. L., et al. (2008). Structural and mutational characterization of the catalytic A-module of the mannuronan C-5-epimerase AlgE4 from Azotobacter vinelandii. J. Biol. Chem. 283, 23819-23828. doi: 10.1074/jbc.M804119200

Rutherford, T. J., Jones, C., Davies, D. B., and Elliott, A. C. (1991). Location and quantitation of the sites of $\mathrm{O}$-acetylation on the capsular polysaccharide from Streptococcus pneumoniae type $9 \mathrm{~V}$ by $1 \mathrm{H}-\mathrm{n} . \mathrm{m} . \mathrm{r}$. spectroscopy: comparison 
with type 9A. Carbohydr. Res. 218, 175-184. doi: 10.1016/0008-6215(91) 84096-W

Sabra, W., Zeng, A. P., Lünsdorf, H., and Deckwer, W. D. (2000). Effect of oxygen on formation and structure of Azotobacter vinelandii alginate and its role in protecting nitrogenase. Appl. Environ. Microbiol. 66, 4037-4044. doi: 10.1128/AEM.66.9.4037-4044.2000

Sadovskaya, I., Vinogradov, E., Flahaut, S., Kogan, G., and Jabbouri, S. (2005). Extracellular carbohydrate-containing polymers of a model biofilm-producing strain, Staphylococcus epidermidis RP62A. Infect. Immun. 73, 3007-3017. doi: 10.1128/IAI.73.5.3007-3017.2005

Sarkisova, S., Patrauchan, M. A., Berglund, D., Nivens, D. E., and Franklin, M. J. (2005). Calcium-induced virulence factors associated with the extracellular matrix of mucoid Pseudomonas aeruginosa biofilms. J. Bacteriol. 187, 43274337. doi: 10.1128/JB.187.13.4327-4337.2005

Schultz, M. P., Bendick, J. A., Holm, E. R., and Hertel, W. M. (2011). Economic impact of biofouling on a naval surface ship. Biofouling 27, 87-98. doi: 10.1080/08927014.2010.542809

Schwab, U., Abdullah, L. H., Perlmutt, O. S., Albert, D., Davis, C. W., Arnold, R. R., et al. (2014). Localization of Burkholderia cepacia complex bacteria in cystic fibrosis lungs and interactions with Pseudomonas aeruginosa in hypoxic mucus. Infect. Immun. 82, 4729-4745. doi: 10.1128/IAI. 01876-14

Shinabarger, D., May, T. B., Boyd, A., Ghosh, M., and Chakrabarty, A. M. (1993). Nucleotide sequence and expression of the Pseudomonas aeruginosa algF gene controlling acetylation of alginate. Mol. Microbiol. 9, 1027-1035. doi: 10.1111/j.1365-2958.1993.tb01232.x

Silbert, J. E., and Sugumaran, G. (2002). Biosynthesis of chondroitin/dermatan sulfate. IUBMB Life 54, 177-186. doi: 10.1080/15216540 214923

Simpson, J. A., Smith, S. E., and Dean, R. T. (1988). Alginate inhibition of the uptake of Pseudomonas aeruginosa by macrophages. J. Gen. Microbiol. 134, 29-36. doi: 10.1099/00221287-134-1-29

Skjåk-Braek, G., Grasdalen, H., and Larsen, B. (1986). Monomer sequence and acetylation pattern in some bacterial alginates. Carbohydr. Res. 154, 239-250. doi: 10.1016/S0008-6215(00)90036-3

Skjåk-Braek, G., Zanetti, F., and Paoletti, S. (1989). Effect of acetylation on some solution and gelling properties of alginates. Carbohydr. Res. 185, 131-138. doi: 10.1016/0008-6215(89)84028-5

Smidsrød, O., and Draget, K. I. (1996). Chemistry and physical properties of alginates. Carbohydr. Eur. 14, 6-13.

Socolofsky, M. D., and Wyss, O. (1961). Cysts of Azotobacter. J. Bacteriol. 81, 946-954.

Speert, D. P., Farmer, S. W., Campbell, M. E., Musser, J. M., Selander, R. K., and Kuo, S. (1990). Conversion of Pseudomonas aeruginosa to the phenotype characteristic of strains from patients with cystic fibrosis. J. Clin. Microbiol. 28, 188-194.

Steigedal, M., Sletta, H., Moreno, S., Maerk, M., Christensen, B. E., Bjerkan, T., et al. (2008). The Azotobacter vinelandii AlgE mannuronan C-5-epimerase family is essential for the in vivo control of alginate monomer composition and for functional cyst formation. Environ. Microbiol. 10, 1760-1770. doi: 10.1111/j.1462-2920.2008.01597.x

Stewart, E. J. (2012). Growing unculturable bacteria. J. Bacteriol. 194, 4151-4160. doi: 10.1128/JB.00345-312

Svanem, B. I., Skjåk-Braek, G., Ertesvåg, H., and Valla, S. (1999). Cloning and expression of three new Aazotobacter vinelandii genes closely related to a previously described gene family encoding mannuronan C-5-epimerases. J. Bacteriol. 181, 68-77.

Svanem, B. I., Strand, W. I., Ertesvåg, H., Skjåk-Braek, G., Hartmann, M., Barbeyron, T., et al. (2001). The catalytic activities of the bifunctional Azotobacter vinelandii mannuronan C-5-epimerase and alginate lyase AlgE7 probably originate from the same active site in the enzyme. J. Biol. Chem. 276, 31542-31550. doi: 10.1074/jbc.M102562200

Szu, S. C., Li, X. R., Stone, A. L., and Robbins, J. B. (1991). Relation between structure and immunologic properties of the Vi capsular polysaccharide. Infect. Immun. 59, 4555-4561.

Terry, J. M., Piña, S. E., and Mattingly, S. J. (1991). Environmental conditions which influence mucoid conversion Pseudomonas aeruginosa PAO1. Infect. Immun. $59,471-477$.
Tielen, P., Strathmann, M., Jaeger, K. -E., Flemming, H. -C., and Wingender, J. (2005). Alginate acetylation influences initial surface colonization by mucoid Pseudomonas aeruginosa. Microbiol. Res. 160, 165-176. doi: 10.1016/j.micres.2004.11.003

Tojo, M., Yamashita, N., Goldmann, D. A., and Pier, G. B. (1988). Isolation and characterization of a capsular polysaccharide adhesin from Staphylococcus epidermidis. J. Infect. Dis. 157, 713-722. doi: 10.1093/infdis/157.4.713

Vanlaere, E., Baldwin, A., Gevers, D., Henry, D., De Brandt, E., Lipuma, J. J., et al. (2009). Taxon K, a complex within the Burkholderia cepacia complex, comprises at least two novel species, Burkholderia contaminans sp. nov. and Burkholderia lata sp. nov. Int. J. Syst. Evol. Microbiol. 59, 102-111. doi: 10.1099/ijs.0.001123-0

Vann, W. F., Schmidt, M. A., Jann, B., and Jann, K. (1981). The structure of the capsular polysaccharide (K5 antigen) of urinary-tract-infective Escherichia coli 010:K5:H4. A polymer similar to desulfo-heparin. Eur. J. Biochem. 116, 359-364. doi: 10.1111/j.1432-1033.1981.tb05343.x

van Selm, S., van Cann, L. M., Kolkman, M. A. B., van der Zeijst, B. A. M., and van Putten, J. P. M. (2003). Genetic basis for the structural difference between Streptococcus pneumoniae serotype $15 \mathrm{~B}$ and 15C capsular polysaccharides. Infect. Immun. 71, 6192-6198. doi: 10.1128/IAI.71.11.6192-6198.2003

Vazquez, A., Moreno, S., Guzmán, J., Alvarado, A., and Espín, G. (1999). Transcriptional organization of the Azotobacter vinelandii algGXLVIFA genes: characterization of algF mutants. Gene 232, 217-222. doi: 10.1016/S03781119(99)00119-5

Veerachamy, S., Yarlagadda, T., Manivasagam, G., and Yarlagadda, P. K. (2014). Bacterial adherence and biofilm formation on medical implants: a review. Proc. Inst. Mech. Eng. H 228, 1083-1099. doi: 10.1177/0954411914556137

Vergara-Irigaray, M., Maira-Litràn, T., Merino, N., Pier, G. B., Penadés, J. R., and Lasa, I. (2008). Wall teichoic acids are dispensable for anchoring the PNAG exopolysaccharide to the Staphylococcus aureus cell surface. Microbiology (Reading, Engl.) 154, 865-877. doi: 10.1099/mic.0.2007/013292-0

Vuong, C., Kocianova, S., Voyich, J. M., Yao, Y., Fischer, E. R., DeLeo, F. R., et al. (2004a). A crucial role for exopolysaccharide modification in bacterial biofilm formation, immune evasion, and virulence. J. Biol. Chem. 279, 54881-54886. doi: 10.1074/jbc.M411374200

Vuong, C., Voyich, J. M., Fischer, E. R., Braughton, K. R., Whitney, A. R., DeLeo, F. R., et al. (2004b). Polysaccharide intercellular adhesin (PIA) protects Staphylococcus epidermidis against major components of the human innate immune system. Cell. Microbiol. 6, 269-275. doi: 10.1046/j.14625822.2004.00367.x

Wang, X., Preston, J. F., and Romeo, T. (2004). The pgaABCD locus of Escherichia coli promotes the synthesis of a polysaccharide adhesin required for biofilm formation. J. Bacteriol. 186, 2724-2734. doi: 10.1128/JB.186.9.2724-2734.2004

Wargo, M. J., and Hogan, D. A. (2006). Fungal-bacterial interactions: a mixed bag of mingling microbes. Curr. Opin. Microbiol. 9, 359-364. doi: 10.1016/j.mib.2006.06.001

Watts, A., Ke, D., Wang, Q., Pillay, A., Nicholson-Weller, A., and Lee, J. C. (2005). Staphylococcus aureus strains that express serotype 5 or serotype 8 capsular polysaccharides differ in virulence. Infect. Immun. 73, 3502-3511. doi: 10.1128/IAI.73.6.3502-3511.2005

Weiman, S., Dahesh, S., Carlin, A. F., Varki, A., Nizet, V., and Lewis, A. L. (2009). Genetic and biochemical modulation of sialic acid $\mathrm{O}$-acetylation on group $\mathrm{B}$ Streptococcus: phenotypic and functional impact. Glycobiology 19, 1204-1213. doi: $10.1093 /$ glycob/cwp111

Weiman, S., Uchiyama, S., Lin, F.-Y. C., Chaffin, D., Varki, A., Nizet, V., et al. (2010). O-Acetylation of sialic acid on Group B Streptococcus inhibits neutrophil suppression and virulence. Biochem. J. 428, 163-168. doi: 10.1042/BJ20100232

Wloka, M., Rehage, H., Flemming, H. -C., and Wingender, J. (2005). Structure and rheological behaviour of the extracellular polymeric substance network of mucoid Pseudomonas aeruginosa biofilms. Biofilms 2, 275-283. doi: $10.1017 /$ S1479050506002031

Wolfram, F., Kitova, E. N., Robinson, H., Walvoort, M., Codée, J. D. C., Klassen, J. S., et al. (2014). Catalytic mechanism and mode of action of the periplasmic alginate epimerase AlgG. J. Biol. Chem. 289, 6006-6019. doi: 10.1074/jbc.M113.533158

Yildiz, F., Fong, J., Sadovskaya, I., Grard, T., and Vinogradov, E. (2014). Structural characterization of the extracellular polysaccharide from Vibrio 
cholerae O1 El-Tor. PLoS ONE 9:e86751. doi: 10.1371/journal.pone.00 86751

Yildiz, F. H., and Schoolnik, G. K. (1999). Vibrio cholerae O1 El Tor: identification of a gene cluster required for the rugose colony type, exopolysaccharide production, chlorine resistance, and biofilm formation. Proc. Natl. Acad. Sci. U.S.A. 96, 4028-4033. doi: 10.1073/pnas.96.7.4028

Zartler, E. R., Porambo, R. J., Anderson, C. L., Chen, L. H., Yu, J., and Nahm, M. H. (2009). Structure of the capsular polysaccharide of pneumococcal serotype 11A reveals a novel acetylglycerol that is the structural basis for 11A subtypes. J. Biol. Chem. 284, 7318-7329. doi: 10.1074/jbc. M807952200
Conflict of Interest Statement: The authors declare that the research was conducted in the absence of any commercial or financial relationships that could be construed as a potential conflict of interest.

Copyright $\odot 2015$ Whitfield, Marmont and Howell. This is an open-access article distributed under the terms of the Creative Commons Attribution License (CC BY).

The use, distribution or reproduction in other forums is permitted, provided the original author(s) or licensor are credited and that the original publication in this journal is cited, in accordance with accepted academic practice. No use, distribution or reproduction is permitted which does not comply with these terms. 